\title{
CHRNA5 belongs to the secondary estrogen signaling network exhibiting prognostic significance in breast cancer
}

\author{
Huma Shehwana ${ }^{1,2,3} \cdot$ Ayse G. Keskus $^{4}$ - Sila E. Ozdemir ${ }^{1}$ • Azer A. Acikgöz ${ }^{1} \cdot$ Rumeysa Biyik-Sit $^{1}$ • Ilgin Cagnan ${ }^{5,6}$. \\ Damla Gunes $^{4} \cdot$ Ermira Jahja $^{1} \cdot$ Sahika Cingir-Koker ${ }^{1} \cdot{\text { Gizem } \text { Olmezer }^{1} \cdot \text { Ceren Sucularli }^{1,7} \cdot \text { Ozlen Konu }}^{1,4,8}$
}

Accepted: 4 December 2020 / Published online: 19 January 2021

(C) Springer Nature Switzerland AG 2021

\begin{abstract}
Purpose Cholinergic signals can be important modulators of cellular signaling in cancer. We recently have shown that knockdown of nicotinic acetylcholine receptor subunit alpha 5, CHRNA5, diminishes the proliferative potential of breast cancer cells. However, modulation of CHRNA5 expression in the context of estrogen signaling and its prognostic implications in breast cancer remained unexplored.

Methods Meta-analyses of large breast cancer microarray cohorts were used to evaluate the association of CHRNA5 expression with estrogen (E2) treatment, estrogen receptor (ER) status and patient prognosis. The results were validated through RT-qPCR analyses of multiple E2 treated cell lines, CHRNA5 depleted MCF7 cells and across a breast cancer patient cDNA panel. We also calculated a predicted secondary (PS) score representing direct/indirect induction of gene expression by E2 based on a public dataset (GSE8597). Co-expression analysis was performed using a weighted gene co-expression network analysis (WGCNA) pipeline. Multiple other publicly available datasets such as CCLE, COSMIC and TCGA were also analyzed.

Results Herein we found that CHRNA5 expression was induced by E2 in a dose- and time-dependent manner in breast cancer cell lines. $\mathrm{ER}^{-}$breast tumors exhibited higher CHRNA5 expression levels than $\mathrm{ER}^{+}$tumors. Independent meta-analysis for survival outcome revealed that higher CHRNA5 expression was associated with a worse prognosis in untreated breast cancer patients. Furthermore, CHRNA5 and its co-expressed gene network emerged as secondarily induced targets of E2 stimulation. These targets were largely downregulated by exposure to CHRNA5 siRNA in MCF7 cells while the response of primary ESR1 targets was dependent on the direction of the PS-score. Moreover, primary and secondary target genes were uncoupled and clustered distinctly based on multiple public datasets.

Conclusion Our findings strongly associate increased expression of CHRNA5 and its co-expression network with secondary E2 signaling and a worse prognosis in breast cancer.
\end{abstract}

Keywords Breast cancer $\cdot$ CHRNA5 $\cdot$ Meta-analysis $\cdot$ Co-expression network $\cdot$ Estrogen receptor targets $\cdot$ Estrogen treatment $~$ Prognosis

Ozlen Konu

konu@fen.bilkent.edu.tr

1 Department of Molecular Biology and Genetics, Faculty of Science, Bilkent University, Ankara, Turkey

2 Department of Biological Sciences, National University of Medical Sciences, Rawalpindi 46000, Pakistan

3 Department of Bioinformatics and Computational Biology, The University of Texas MD Anderson Cancer Center, Houston, TX, USA

4 Interdisciplinary Program in Neuroscience, Bilkent University, 06800 Ankara, Turkey
5 Department of Biological Sciences, Faculty of Arts and Sciences, Eastern Mediterranean University, Famagusta, North Cyprus, Turkey

6 Department of Stem Cell Sciences, Graduate School of Health Sciences, Center for Stem Cell Research and Development, Hacettepe University, 06100 Ankara, Turkey

7 Department of Bioinformatics, Institute of Health Sciences, Hacettepe University, 06100 Ankara, Turkey

8 UNAM-Institute of Materials Science and Nanotechnology, Bilkent University, 06800 Ankara, Turkey 


\section{Introduction}

Cholinergic receptor nicotinic alpha 5 (CHRNA5) is encoded by one of the several nicotinic acetylcholine receptor (nAChR) subunit genes located on chromosome 15, i.e., CHRNA5, CHRNA3 and CHRNB4 [1]. Upregulated expression of CHRNA5 [2], downregulation of CHRNA3 [2] and epigenetic regulation of CHRNB4 [3] in lung cancer implicate the involvement of these loci in cancer genetics. CHRNA5 has various isoforms due to alternative splicing of the exon $\mathrm{V}[4$, 5], and multiple isoforms are overexpressed in lung cancer in comparison to normal lung tissue [4]. Studies have revealed potential implications of several other cholinergic receptor subunits in estrogen (E2) signaling and breast cancer. For example, CHRNA4 is regulated by E2 in a site-specific manner in brain [6]. Similarly, CHRNA9 expression increases in response to E2 in the MCF7 cell line and patient data show a positive correlation between the ER status and CHRNA9 expression [7]. In addition, CHRNA9 overexpression has been associated with increased proliferative potential in non-tumor breast cell lines, whereas CHRNA9 knockdown led to smaller tumor volumes in a breast cancer xenograft model in mice [8]. Recently, we have demonstrated that CHRNA5 depletion in breast cancer cells by RNAi is associated with cell cycle inhibition, increased apoptosis and drug sensitivity [9]. Nevertheless, there is no comprehensive study yet analyzing changes in CHRNA5 isoform expression in breast cancer cells in response to $\mathrm{E} 2$ or across $\mathrm{ER}^{+} / \mathrm{ER}^{-}$breast tumors. Moreover, CHRNA5 expression along with its co-expression network has not been studied in the context of breast cancer prognosis.

E2 exerts its actions in genomic terms via ER alpha $(\alpha)$ (ESR1) and/or beta ( $\beta$ ) (ESR2), or through non-genomic pathways mediated by $\mathrm{G}$ protein-coupled estrogen receptor 1 (GPER1) [10]. The E2-bound ER complex is targeted to specific sequences on DNA (estrogen response elements, EREs), upstream of target genes, altering their transcription [11]. Alternatively, the E2-bound ER complex may induce expression of various transcription factors (TF), exerting a global effect, secondarily [11]. Thus, E2 may regulate gene expression time dependently via interactions with ER primarily and/ or secondarily by TFs which are directly induced/repressed by ER $[12,13]$. ER status still remains one of the most significant determinants of therapy choice and outcome in breast cancer [14]. Therefore, it is important to investigate the differential contribution of primary and secondary target genes to $\mathrm{ER}^{+}$and $\mathrm{ER}^{-}$breast cancer prognosis [15].

Combining gene expression signatures with clinical survival data enables prioritization of prognostic biomarkers for therapeutic targeting [16]. Hazard ratio (HR) is a widely used statistical measure to predict prognostic outcome in terms of risk of tumor relapse, metastasis or patient death [17]. Previous studies generally have focused on a small subset of genes and gene clusters while addressing the diagnostic/ prognostic power of E2-regulated gene expression in cancer $[18,19]$. Moreover, meta-analysis approaches via combining multiple similar-context transcriptomics studies to increase sample size and statistical power can be used to improve breast cancer prognostication [20-22]. However, a transcriptome-wide meta-correlation analysis between the expression level and clinical outcome for the primary or secondary targets of E2-signaling has not been performed.

In the present study, we employed meta-analyses as well as RT-qPCR to establish the association of CHRNA5 expression response to E2 treatment and to ER status using in vitro cell line and in vivo patient tumor data, respectively. Our analysis revealed a negative correlation between CHRNA5 mRNA expression and that of ESR1 based on multiple independent datasets. Meta-survival analysis indicated that higher CHRNA5 expression levels were associated with a worse prognosis in untreated breast cancer patients. We next found that genes positively co-expressed with CHRNA5 were also associated with a worse prognosis, over-expressed in $\mathrm{ER}^{-}$ breast cancer patients and enriched with secondary E2 targets. Comparative transcriptomics analyses performed with the expression profile of CHRNA5 siRNA-treated MCF7 cells supported the newly discovered involvement of CHRNA5 in E2 signaling in breast cancer. Our study revealed an uncoupling between E2-modulated primary and secondary cellular signaling upon CHRNA5 depletion and a co-expression network of CHRNA5 with significant prognostic implications in breast cancer.

\section{Materials and methods}

\subsection{In vitro expression data}

Microarray gene expression datasets (Affymetrix platform GPL570/96/571) were obtained from the GEO database [23, 24] for E2-treated $\mathrm{ER}^{+}$breast cancer cell line MCF7 (Supplementary Table 1) using keywords, i.e., MCF7 and/or estrogen (Supplementary Methods).

\subsection{Breast cancer patient expression data}

For TCGA dataset analyses, RNAseq normalized count data (RSEM) of breast cancer patients along with ER status of breast cancer patient data were downloaded from FireBrowse (http://firebrowse.org). Breast cancer patient microarray datasets used for meta-analysis were split in two cohorts: an ER cohort assembled from the GEO database [24] directly (Supplementary Table 2) and a survival cohort based on untreated patient data from the KM Plotter database (Supplementary Table 3) [25]. Retrieval and processing of meta-analysis cohorts are described in detail in Supplementary Methods. 


\subsection{Meta-differential expression analysis}

Meta-analyses of E2 treated MCF7 datasets and $\mathrm{ER}^{+} / \mathrm{ER}^{-}$ subtype patient datasets were conducted separately following PRISMA guidelines (Supplementary Figs. 1 and 2). For transcriptome-wide differential expression, metaDE [26] and for forest plots, meta [27] packages were used, respectively (details in Supplementary Methods).

\subsection{Survival meta-analysis}

Survival analysis of individual datasets of the survival cohort (Supplementary Table 3; Supplementary Fig. 3) was performed using the survival package along with the customized $\mathrm{R}$ code provided by KM Plotter using Cox proportional hazard model and auto cut-off selection (Supplementary Methods) [25]. Hazard Ratio (HR) scores obtained for each dataset were combined by meta [27] package to get metaHazard Ratios (meta-HRs) using the fixed and random effect models (FEM and REM, respectively).

\subsection{Determination of secondarily induced targets of E2 signaling based on the GSE8597 dataset}

The GSE8597 dataset [12], retrieved from the GEO database, consisted of four treatment groups in MCF7 cells, i.e., (1) E2, (2) $\mathrm{EtOH}$, (3) $\mathrm{CHX}+\mathrm{E} 2$ and (4) $\mathrm{CHX}$ treatments. A limma analysis was performed for each probeset between samples treated with E2 and with EtOH to identify E2-driven gene expression changes (Limma_E2). To analyze the secondary responses mediated by E2 exposure, expression data from E2 and $\mathrm{CHX}+\mathrm{E} 2$ treated samples were first normalized to the mean expression value of EtOH and $\mathrm{CHX}$ control samples, respectively, before performing limma (Limma_PS: E2 $i$ mean $(\mathrm{EtOH})$ vs. $\mathrm{CHX}+\mathrm{E} 2 i-\operatorname{mean}(\mathrm{CHX})$, where $i$ refers to probeset ID). $\operatorname{LogFC}$ values from Limma_PS analysis represented Predicted Secondary scores (PS-scores). E2 induced secondary targets were further determined upon filtering of: (1) E2 induced probesets (Limma_E2: $\operatorname{LogFC}>0.5$ and $p<0.05)$ and $(2)$ probes showing secondary responses (Limma_PS: $\operatorname{LogFC}>0.5$ and $p<0.05$ ). 367 probesets passed these filters. PS-scores were further used in correlation analyses.

\subsection{Meta-correlation and co-expression network analysis}

Correlation coefficients between each gene and CHRNA5 for both the ER cohort and the survival cohort were calculated separately using DerSimonian-Laird (DSL) randomeffect meta-analysis with the help of the Metacor bioconductor package [28]. On the other hand, the CHRNA5 co-expression network was based only on $E R$ cohort meta-correlation analysis (details in Supplementary Methods). Signed WGCNA (weighted gene co-expression network analysis) was used for the identification of CHRNA5 associated co-expression modules [29]. Top positive and top negative co-expression modules and associated data were visualized in Cytoscape [30] using interactions from the STRING database [31]. iRegulon plugin [32] of Cytoscape was used to find the TF enrichments in each module. Functional annotation of co-expression modules for KEGG pathways was done using DAVID (version 6.8 Beta) $(\mathrm{BH}<0.05)$ [33]. Additionally, the Harmonizome data portal [34] was used to retrieve transcription factor binding sites of the CHRNA5 gene by selecting four datasets (CHEA, ENCODE, JASPAR and TRANSFAC transcription factors).

\subsection{TCGA breast cancer data analysis}

Log (base 2) transformed RSEM (+1) counts were used for principal component analysis (PCA) of gene lists specified in the results section (see figure legends for futher details). In case of multiple samples from the same patient, average RSEM was used (1212 total samples and 1093 unique samples). Correlation analysis was performed between the expression values of CHRNA5 and those of every other gene using Spearman's correlation coefficient in MATLAB. Clustering was done based on linkage and distance parameters as described previously [9]. mRNA expression of $R B 1$ and CHRNA5 along with copy number alteration (CNA) and ER status data were obtained from TCGA via cbioportal [35]. Patients with "indeterminate" ER status were removed prior to plotting $(n=1026)$. A two-way ANOVA was performed in $\mathrm{R}$ environment.

\subsection{Comparative transcriptomics after CHRNA5 siRNA exposure in MCF7 cells}

The primary target gene list in response to E2 exposure in MCF7 cells was obtained from a published ChIP-seq interaction study [36]. The expression profile of CHRNA5 siRNAtreated and that of scrambled siRNA-treated MCF7 cells have been previously analyzed (GSE89333; [9]). We used jetset best probesets to find the common probesets between the GPL96 and GPL570 platforms [37] and data from GSE89333 were compared with those from (a) GSE8597 [12] to determine the correlation of CHRNA5 siRNA treatment with E2 primary (ChIP-seq targets [36]) and secondary targets (predicted using GSE8597) [12] and (b) GSE4668 [38] to investigate the association of E2 stimulation and hormone starvation with the expression profile of CHRNA5 depletion in MCF7 cells. 


\subsection{Cell culturing after dose- and time-dependent E2 exposure}

MCF7, MDA-MB-231, CAL-51, ZR-75-1 and T47D breast cancer cell lines were treated with $\beta$-estradiol (E2, $2 \mathrm{mM}$ stock solution in EtOH; E2758, 32221, Sigma Aldrich, Missouri, USA) of $1 \mathrm{nM}, 10 \mathrm{nM}$, and/or $100 \mathrm{nM}$ as described below. For dose-dependent exposures, $1 \times 10^{6} \mathrm{MCF} 7$ and MDAMB-231 cells seeded into T75 flasks were incubated with 10\% FBS (SH30021.01, SW30160.0, HyClone, Logan, USA) in phenol red supplemented DMEM growth medium with $1 \%$ penicillin/streptomycin solution and $1 \%$ nonessential amino acids for $24 \mathrm{~h}$. Media were then replaced with phenol red-free DMEM with 5\% charcoal dextran-treated FBS with supplements for $72 \mathrm{~h}$. Synchronization performed for $24 \mathrm{~h}$ in phenol red-free Dulbecco's MEM (F0475, Biochrom AG, Berlin, Germany) with $0.1 \%$ charcoal/ dextran-treated FBS (and with the rest of the additives from the $5 \%$ medium) was followed by $\beta$-estradiol (E2, $2 \mathrm{mM}$ stock solution in EtOH; E2758, 32221, Sigma Aldrich, Missouri, USA) of $1 \mathrm{nM}, 10 \mathrm{nM}$, and $100 \mathrm{nM}$ for $24 \mathrm{~h}$ ( $n=2$ per dose). For the time-dependent exposure, MCF7 cells were seeded at a density of $1 \times 10^{6}$ cells into T75 flasks and the same procedure as above was applied (100 nM; $12 \mathrm{~h}$ and $24 \mathrm{~h}$ ). E2 was dissolved in EtOH and the sample size per group equaled to two for all experiments. EtOH was used as control group. Similarly, $2 \times 10^{5}$ T47D, $2.5 \times 10^{5}$ ZR-75-1 and $1.5 \times$ $10^{5}$ CAL-51 cells were seeded in 6-well plates before being treated with $10 \mathrm{nM} \mathrm{E} 2$ for $24 \mathrm{~h}$ as above.

\subsection{RNA isolation and CDNA synthesis}

Total RNA was isolated using a RNeasy Mini kit (74,104, Qiagen, Hamburg, Germany) or QIAzol Lysis Reagent (cat. no. 79306) after which $1 \mu \mathrm{g}$ total RNA was reverse transcribed using a RevertAid first strand cDNA synthesis kit (K1622, Fermentas, Ontario, Canada) according to the manufacturer's protocols. Primer details for CHRNA5 isoforms and reference genes are provided in Supplementary Table 4. A breast cancer tissue cDNA panel (BCRT501) was purchased from OriGene (Rockville, USA) and diluted in a ratio of 1:20 using $\mathrm{ddH}_{2} \mathrm{O}$ before use.

\subsection{RT-qPCR analysis and primers}

A Roche Light Cycler (LC480 II; Roche, Basel, Switzerland) was used for RT-qPCR with an initial incubation at $95^{\circ} \mathrm{C}$ for 5 min followed by $95{ }^{\circ} \mathrm{C}$ for $10 \mathrm{~s}$ and $20 \mathrm{~s}$ at $60{ }^{\circ} \mathrm{C}$ for 50 cycles in duplicates using a $10 \mu \mathrm{l}$ reaction volume containing $5 \mu \mathrm{l} \mathrm{SYBR}$ green Master Mix (04707516001, Roche, Basel, Switzerland), $2 \mu \mathrm{l}$ cDNA, $2 \mu$ l Forward and Reverse

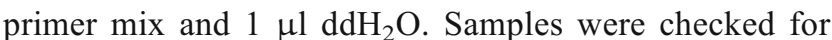
amplicon-specific melting temperatures $(\mathrm{Tm})$ and those with duplicate Tm values as well as $\mathrm{Ct}$ readings with \pm 1 standard deviation away from the median plate Tm value were removed. Relative expression was calculated using TPT1 as a reference gene [39, 40]. The TFF1/PS2 gene was used as a positive control [41-43] to test for induction by E2 stimulation (Supplementary Table 4). Upon calculation of relative expression levels [44] logarithmically (base 2) transformed units were plotted as barplots using GraphPad software (California, USA). Primer pairs used for CHRNA5 isoforms were previously reported (CHRNA5_v1 and CHRNA5_v2 from [9] and CHRNA5_v3 from [5] and iso2 and iso3 from [4]; Supplementary Table 4 ). In addition, primers for selected primary and secondary targets of E2 signaling were designed and tested by RT-qPCR using cDNA samples obtained from $10 \mathrm{nM}$ [9] as well as $20 \mathrm{nM}$ and $50 \mathrm{nM}$ treatments of CHRNA5 siRNA or scrambled oligo siRNA (Supplementary Table 4).

\section{Results}

\subsection{Meta-analysis reveals that CHRNA5 expression is responsive to E2 in $\mathrm{ER}^{+}$cell lines}

Meta-analysis of E2 treatment in MCF7 cell line expression datasets showed a significant increase in the CHRNA5 probeset "206533_at" (Supplementary Table 1; Fig. 1a) starting from the sixth hour of E2 treatment (late E2 treatment cohort; FEM: $\mathrm{z}$-value $=5.04 ; p=4.5 \mathrm{e}-07$ REM: $\mathrm{z}$-value $=$ 3.28; $p=0.001$ ) while no significant change in CHRNA5 expression was observed during the initial hours of $\mathrm{E} 2$ treatment (Supplementary Fig. 4a). CHRNA5 expression was also induced in T47D cells and to a lesser degree in ESR1 mutated MCF7- and T47D-derived cell lines (Supplementary Fig. 4b). The ESR1 mutations (D538G and Y537S) were presumed to be responsible for ligand-independent ER regulation [45]. These findings suggest that CHRNA5 expression positively responds to $\mathrm{E} 2$ treatment in $\mathrm{ER}^{+}$cell lines in a timedependent manner and could be a potential target gene upon E2 modulation.

Based on the meta-analysis results, two different time points $(12 \mathrm{~h}$ and $24 \mathrm{~h})$ were selected to evaluate E2mediated CHRNA5 isoform expression changes using RTqPCR. $24 \mathrm{~h}$ of E2 treatment effectively modulated E2dependent signaling, as shown by a significant increase in TFF1/PS2 expression. All CHRNA5 isoforms showed significant increases upon $24 \mathrm{~h}$ of E2 treatment in MCF7 cells, while CHRNA5 iso2 also exhibited a milder but significant upregulation even at $12 \mathrm{~h}$ (Fig. 1b). The results were further validated in two other $\mathrm{ER}^{+}$cell lines (T47D and ZR-75-1) and a consistent pattern of significant upregulation of all CHRNA5 isoforms was observed after $24 \mathrm{~h}$ of E2 treatment (Supplementary Fig. 4c). Our results confirm that CHRNA5 
a CHRNA5 (206533_at)

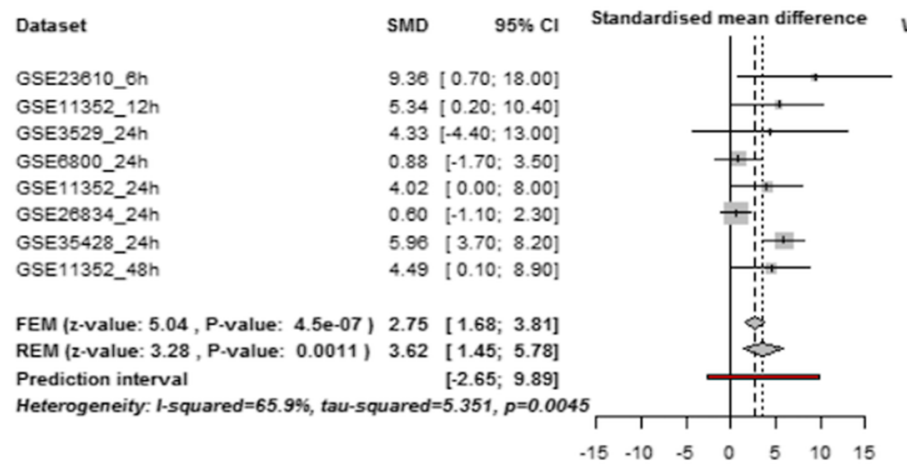

C

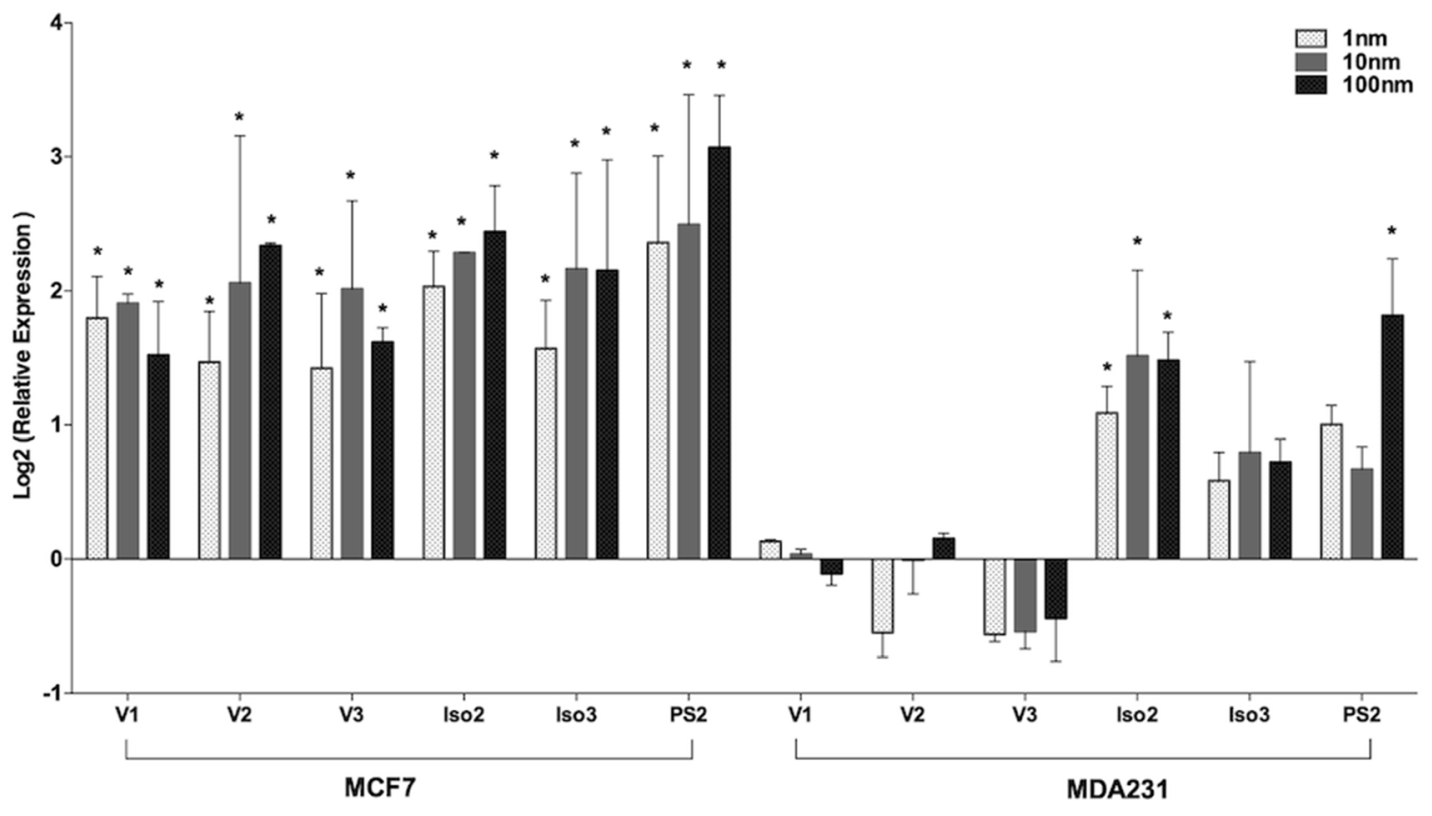

d

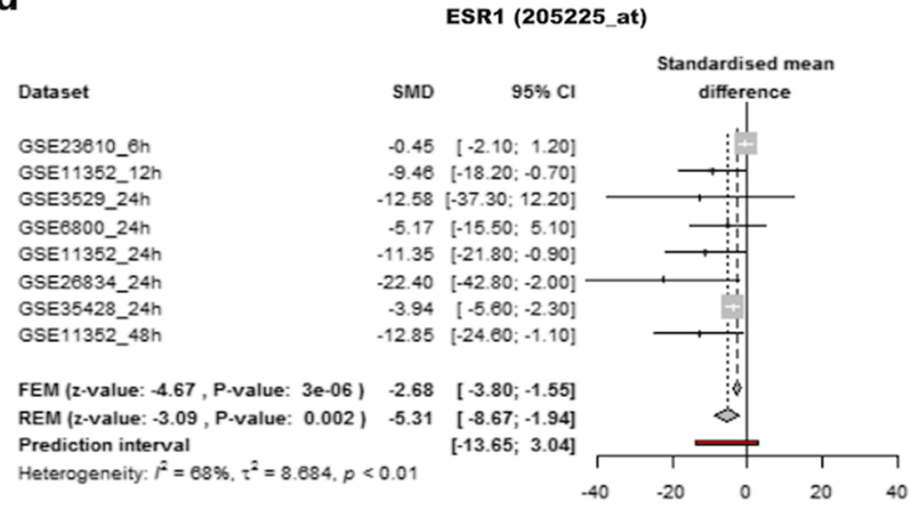

b

W(fixed) W(random)

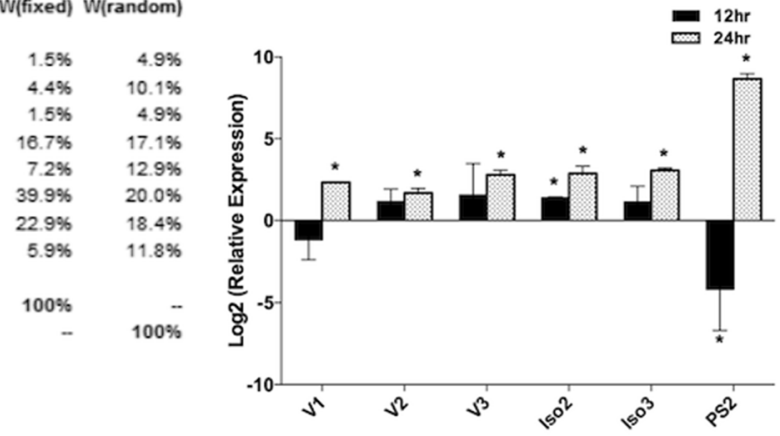

nm

$\mathrm{nm}$ 
is an E2 responsive gene and that the phenomenon is consistent among different $\mathrm{ER}^{+}$cell lines.

\subsection{E2 affects CHRNA5 expression differently in $\mathrm{ER}^{+}$ and ER $^{-}$cell lines}

The dose-dependent effect of E2 treatment on expression of CHRNA5 isoforms was evaluated in MDA-MB-231, an ER ${ }^{-}$ cell line, in comparison to MCF7 cells $\left(\mathrm{ER}^{+}\right)$. Increased expression of CHRNA5 was prominent for all isoforms even at $1 \mathrm{nM} \mathrm{E} 2$ exposure for $24 \mathrm{~h}$ in MCF7 cells. However, isoform expression was variably affected by E2 in MDA-MB-231 cells with a mild but significant induction of CHRNA5 Iso2 for all three concentrations (Fig. 1c). Another $\mathrm{ER}^{-}$cell line, CAL-51, showed no significant regulation of CHRNA5 isoforms upon E2 treatment after $24 \mathrm{~h}$ of E2 treatment (Supplementary Fig. 4c). Our findings show that the effect of E2 on CHRNA5 isoform expression varies with the ER status of the cell lines.

Meta-analysis of the late E2 treatment cohort in MCF7 cells confirmed that increased expression of CHRNA5 in response to E2 (Fig. 1a) was indeed accompanied by significant ESR1 downregulation, thus highlighting a negative association between the two genes at the transcriptional level (Fig. 1d; Supplementary Fig. 4d). Analysis of 50 different COSMIC breast cancer cell lines validated that the negative correlation between CHRNA5 and ESR1 levels was not specific to MCF7 ( $\mathrm{r}=-0.42 ; p=0.003$; Fig. 1e). Furthermore, in CCLE breast cancer cells a negative association of CHRNA5 (mRNA) with ESR1 could be observed at both the transcript and protein level (ESRI (mRNA): $\mathrm{r}=-0.34, p=2.11 \mathrm{e}-02$; Total ER-alpha (protein): $\mathrm{r}=-0.37, p=9.4 \mathrm{e}-03$; ER-alphapS118 (protein): $\mathrm{r}=-0.41, p=4.6 \mathrm{e}-03$ ) (Supplementary Fig. 5).

\subsection{CHRNA5 expression is upregulated in breast tumors}

Using patient tumor data, differential expression analysis (meta-analysis) on the basis of IHC (immunohistological status) of ER (ER cohort: 31 datasets; $1255 \mathrm{ER}^{-}$and $1650 \mathrm{ER}^{+}$ breast cancers; details in Supplementary Table 2) indicated that the expression of CHRNA5 was significantly higher in the $\mathrm{ER}^{-}$breast tumors than in the $\mathrm{ER}^{+}$breast tumors, with high heterogeneity but no publication bias (I-squared = 72.6\%; Z-score $=7.4 ; p=1.4 \mathrm{e}-13$; Fig. 2a; Egger's test $p=$ 0.99; Supplementary Fig. 6). The inverse correlation between CHRNA5 and ER status could also be observed at the transcript level in the same ER cohort datasets, indicating a high concordance between IHC- and microarray-based ER level results (Supplementary Fig. 7), as well as in the TCGA RNA-seq breast cancer data (1093 patients) (Fig. 2b). These findings indicate that although induced by E2, CHRNA5 was overexpressed in $\mathrm{ER}^{-}$tumors.

RT-qPCR validation using a breast cancer cDNA panel revealed that three of the isoforms (V3, Iso2, Iso3) were significantly overexpressed in $\mathrm{ER}^{-}$compared to $\mathrm{ER}^{+}$samples (Fig. 2c). Comparison with the normal samples showed that all of the CHRNA5 isoforms exhibited a higher expression in tumor samples than in normals. After splitting the normal/ tumor analysis to subtypes on the basis of ER status, all isoforms were significantly overexpressed in $\mathrm{ER}^{-}$tumors while only CHRNA5_Iso3 and CHRNA5_V1 showed significantly higher expression levels in $\mathrm{ER}^{+}$breast tumors compared to normals. These findings support our meta-analysis results indicating that CHRNA5 exhibited a relatively higher expression in $\mathrm{ER}^{-}$than in $\mathrm{ER}^{+}$patients while showing isoform specificity (Fig. 2c).

\subsection{High CHRNA5 expression indicates a poor prognosis for breast cancer patients}

Using an independent patient cohort (survival cohort; 5 datasets; 894 patients; Supplementary Table 3), meta-survival analysis results showed that a higher CHRNA5 expression was associated with a poor prognosis in untreated breast cancer patients (FEM zvalue $=2.73 ; p=0.0063$; Fig. 3a). Both meta-analysis models (FEM and REM) showed similar and significant meta-hazard ratios, yet the fixed effect model (FEM) results may be more appropriate since the survival cohort exhibited no significant heterogeneity $\left(\mathrm{I}^{2}=47.4 \% ; p=0.1\right)$.

\subsection{CHRNA5 co-expression network is associated with ER status and breast cancer prognosis}

Transcriptome-wide differential expression of $\mathrm{ER}^{-}$breast tumors with reference to $\mathrm{ER}^{+}$tumors (effect size, i.e., standardized mean difference from the ER cohort) showed a strong positive correlation with the CHRNA5 meta-correlation profile (survival cohort; significant genes $(p<0.05), \mathrm{r}=0.88$; Fig. 3b). Comparative analysis showed that CHRNA5 itself and genes positively correlated with CHRNA5 were overexpressed in $\mathrm{ER}^{-}$patients, while the expression levels of negatively correlated genes were downregulated in $\mathrm{ER}^{-}$ patients (Fig. 3b). Similarly, genes positively co-expressed with CHRNA5 exhibited high hazard ratios (meta-HR values) and were associated with a worse prognosis among untreated breast cancer patients as shown by the color spectrum on the graph (Fig. 3b and c).

\subsection{CHRNA5 co-expression modules show functional enrichment and differential HR}

Classification of the CHRNA5 co-expressed genes (obtained using WGCNA) revealed six distinct modules, 
a

Datase

GSE11001

GSE5460

GSE25055

GSE21653

GSE50948

GSE48390

GSE 453365

GSE42822

GSE 42568

GSE37946

GSE 36771

GSE32072

GSE25065

GSE24185

GSE23988

GSE23720

GSE22597

GSE22093

GSE20711

GSE2027

GSE17907

GSE2603

GSE18728

GSE76274

GSE 43358

GSE51450

GSE 32646

GSE1886

GSE20194

FEM (2-value: 15.06, p-value: 3.1e-51)

REM (2-value: 7.4, , P-value: $1.4 \mathrm{e}-13$ )

Prediction interval

Heterogeneity: l-squared-72.65, tau-squared-0. 1329, p<0.000 $\begin{array}{cc}\text { ER- } & \text { ER+ } \\ \text { Samples Samples } & \text { SMD }\end{array}$ $741.500 .2000[1.10 ; 1.90]$

$1290.580 .1300[0.30 ; 0.80]$

$\begin{array}{lll}52 & 0.48 & 0.1700[0.10 ; 0.80]\end{array}$

$\begin{array}{lll}53 & 0.430240010,00: 0000\end{array}$

(1) $0.430 .18001000,00700$

$830.380 .1800[0.00 ; 0.70]$

(9.7. $0.520 .4000[1.20 .2 .40$

$90.520 .4000[-0.30,1.30]$

$\begin{array}{lll}67 & -0.33 & 0.2100\end{array}[-0.70 ; 0.10]$

$\begin{array}{lll}16 & 0.41 & 0.3400[-0.30 ; 1.10]\end{array}$

$79 \begin{array}{ll}1.310 .2400[0.80 ; 1.80] \\ 6\end{array}$

6
$0.780 .6100[-0.40 ; 2.00]$

$230.420 .1500[0.10 ; 0.70]$

$58-0.100 .2000[-0.50 ; 0.30]$

$270.630 .2800[0.10 ; 1.20]$

$33 \quad 0.340 .3100[-0.30 ; 0.90]$

$160.280 .3200[-0.30 ; 0.90]$

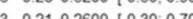

23 $0.210 .2600[-0.30 ; 0.70]$

. $0.640 .2200<10.20,1.100$

$0.460 .1700-[0.10,0.80]$

$220.510 .3000[-0.10 ; 1.10$

$570.950 .2100[0.50 ; 1.40]$

$10 \quad 0.280 .4500[-0.60 ; 1.20]$

$\begin{array}{lll}49 & 0.19 & 0.2800[-0.30 ; 0.70]\end{array}$

$381.680 .3200[1.00 ; 2.30]$

$60.050 .5800[-1.10 ; 1.20]$

$710.720 .2000[0.30: 110]$

$1390.790 .1400[0.50: 1.10]$

$280.670 .2500[0.20 ; 1.20]$

$6.1100 .47001020 ; 200$

$1450.720 .1300[0.50 ; 1.00]$

$\begin{array}{lll}1650 \quad 0.60 & {[0.52 ; 0.68]}\end{array}$

0.60
$140.060 .4100[-0.70 ; 0.90]$

Standardised mean ditterence

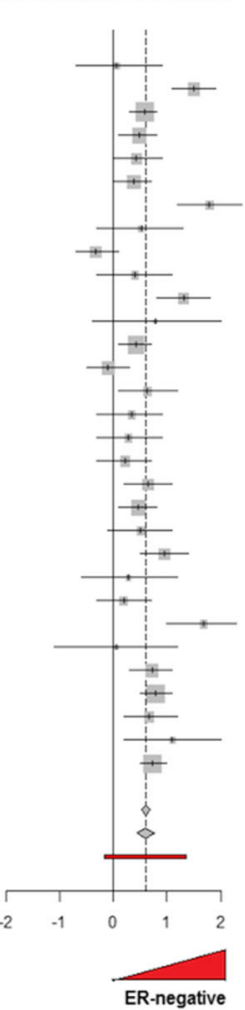

ER-negative

Fig. 2 CHRNA5 is over-expressed in $\mathrm{ER}^{-}$breast cancer patients. a Metadifferential expression of CHRNA5 in $\mathrm{ER}^{-}$breast cancer patients compared with $\mathrm{ER}^{+}$breast cancer patients (ER cohort; 31 datasets). b Correlation between CHRNA5 and ESRI expressions using TCGA RNA-seq gene normalized data. $\mathbf{c}$ Validation of the expression of

three of which were positively and the other three were negatively co-expressed with CHRNA5 (Fig. 4a). Functional annotation using KEGG pathways showed that positively co-expressed modules were involved in cell cycle, DNA replication and repair, and p53 signaling pathways, while negatively co-expressed modules were rather enriched with focal adhesion and extracellular matrix adhesion pathways (Table 1), supporting our previously reported findings [9]. In addition, the turquoise module (positively co-expressed) indicated the role of CHRNA5 in addiction pathways including those of nicotine and morphine, as well as in retrograde endocannobinoid signaling, neuroactive ligand-receptor interaction and calcium signaling (Table 1). Overlaying modular information with our meta-analysis scores strengthened our previous finding that positively coexpressed modules were enriched with genes overexpressed in the $\mathrm{ER}^{-}$tumors $\left(\mathrm{FDR}<0.05\right.$ and $\mathrm{ER}^{-} /$ $\mathrm{ER}^{+}$treatment effect $>0$; Fig. $4 \mathrm{~b}$ ), while exhibiting a worse prognosis $(p<0.05$ and meta-HR $>0$; Fig. $4 c)$ and vice-versa. b

W(fixed) W(random)

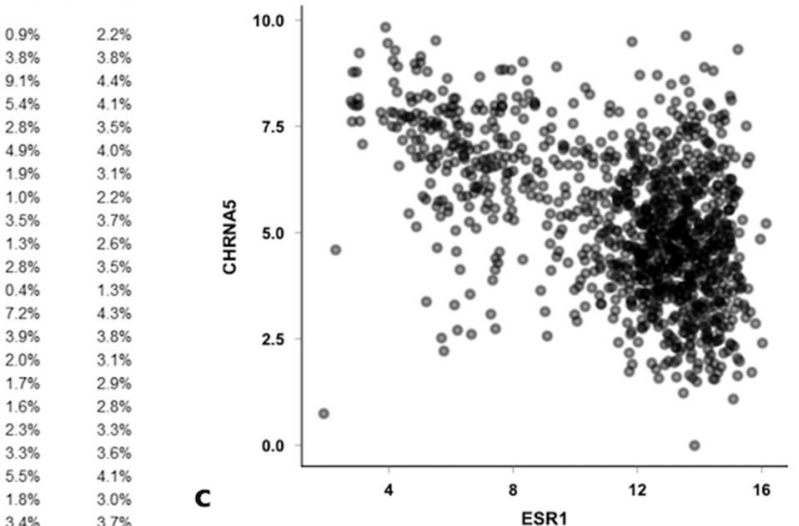

$3.7 \%$

$0.8 \% \quad 2.0 \%$

$\begin{array}{ll}2.1 \% & 3.2 \% \\ 1.5 \% & 2.8 \%\end{array}$

$0.5 \% \quad 1.4 \%$

$4.0 \% \quad 3.8 \%$

$\begin{array}{ll}8.5 \% & 4.4 \% \\ 2.6 \% & 3.4 \%\end{array}$

$\begin{array}{ll}2.6 \% & 3.4 \% \\ 0.7 \% & 1.9 \%\end{array}$

$\begin{array}{ll}0.7 \% & 1.9 \% \\ 8.8 \% & 4.4 \%\end{array}$

1005

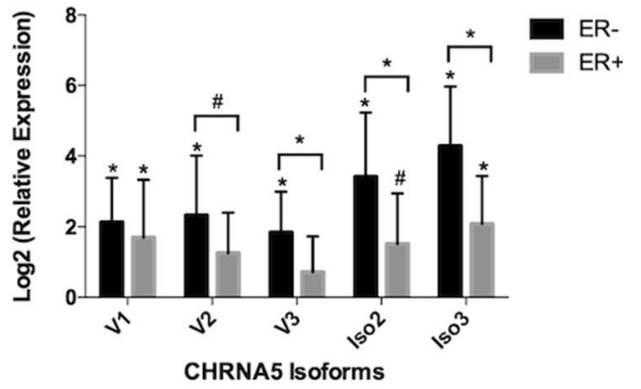

CHRNA5 isoforms in the cDNA panel using RT-qPCR. Statistical analysis was performed using ANOVA and post-hoc Tukey HSD tests. FEM: Fixed Effect Model; REM: Random Effect Model; SMD: Standardized Mean Difference; $r$ : Correlation Coefficient. * Indicates $p<0.05$, \# Indicates $p<0.1$

\subsection{Top positive CHRNA5 co-expression module is enriched with E2-induced secondary targets}

Protein-protein interactions of top ranked positive (yellow) and negative (brown) modules from WGCNA revealed highly connected networks (Fig. 5 and Fig. 6, respectively). Expectedly, transcription factor (TF) enrichment analysis of the CHRNA5 co-expressed module showed regulation by ER-alpha (ESR1) in the negatively co-expressed module (Fig. 6). Multiple members of the E2F family were among the enriched TFs in the top most positive CHRNA5 co-expression module (Fig. 5). In addition, the promoter of the CHRNA5 gene itself had binding sites for E2F members (E2F1, E2F4, E2F6) and multiple other enriched transcription factors including SIN3A, NFYB and ZIN143, but not for ESR1 (ENCODE database; Harmonizome portal; Supplementary Table 5). Enrichment of E2F1 in the CHRNA5 promoter site and its co-expressed module highlighted that the CHRNA5 coexpressed network could be a downstream target of E2F1 and/or indirectly regulated by the E2 response. 
a

$\begin{array}{lrr}\text { Dataset } & \text { TE } & \mathbf{9 5 \%} \mathbf{C l} \\ \text { GSE2034 } & 0.66[0.30 ; 1.10] \\ \text { GSE3494 } & 0.41[-0.20 ; 1.00] \\ \text { GSE2990 } & 0.40[-0.40 ; 1.20] \\ \text { GSE7390 } & 0.17[-0.30 ; 0.60] \\ \text { GSE11121 } & -0.29[-0.90 ; 0.30] \\ & & \\ \text { FEM (z-value: } 2.73, \text { P-value: } \mathbf{0 . 0 0 6 3}) & \mathbf{0 . 3 2} & {[\mathbf{0 . 0 9} ; 0.55]} \\ \text { REM (z-value: } \mathbf{1 . 7}, \text { P-value: } \mathbf{0 . 0 8 9}) & \mathbf{0 . 2 9} & {[-0.04 ; 0.62]} \\ \text { Prediction interval } & & {[-0.69 ; 1.27]} \\ \text { Heterogeneity: } I^{2}=47 \%, \tau^{2}=0.0659, p=0.11\end{array}$

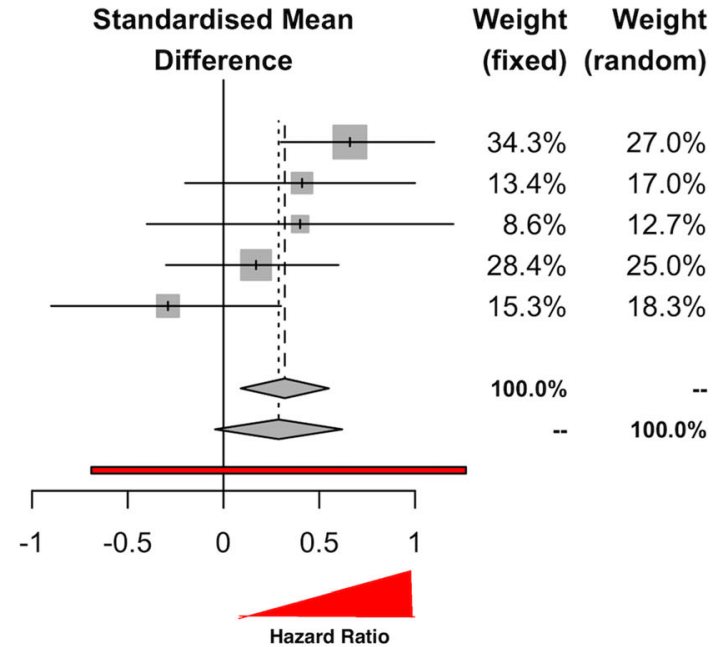

b

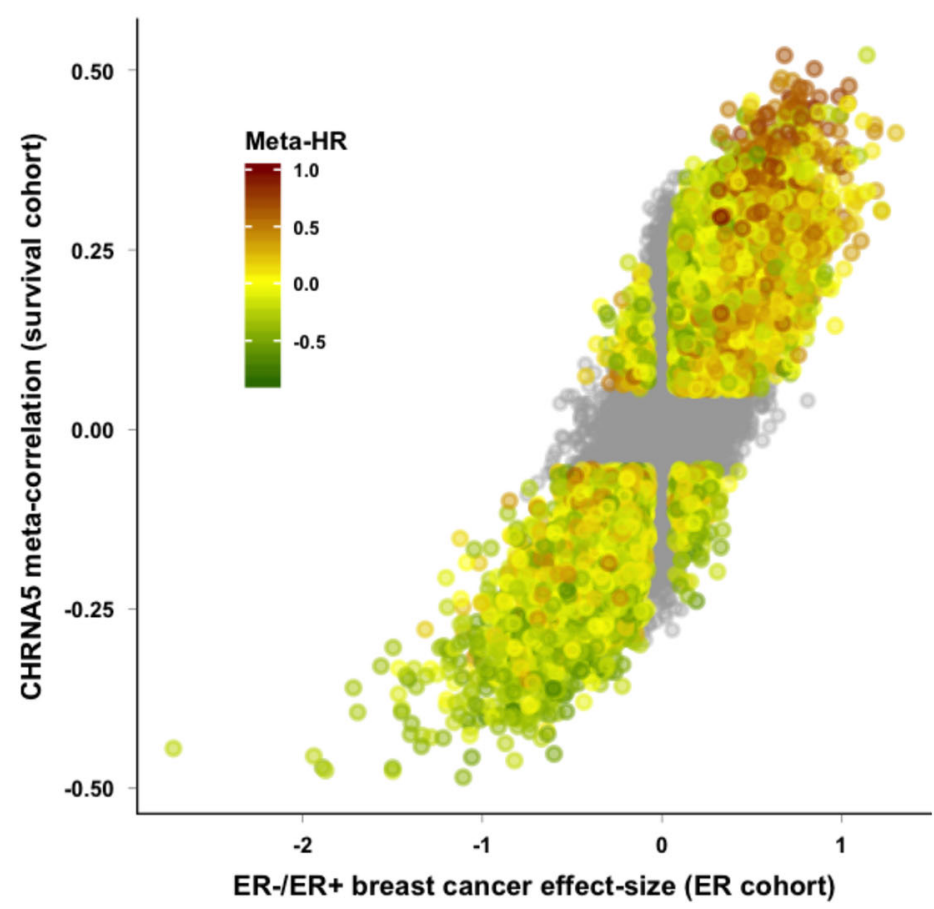

All probesets: $r=0.78, p<2.2 \mathrm{e}-16$ Significant probesets: $r=0.88, p<2.2 e-16$

C

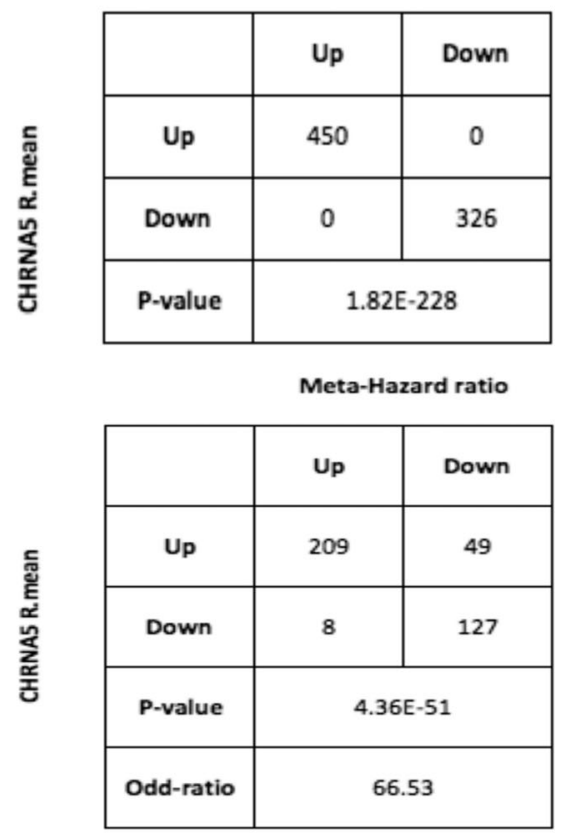

Fig. 3 CHRNA5 and its co-expressed genes are associated with a worse prognosis and are over-expressed in the $\mathrm{ER}^{-}$breast cancer subtype. a Meta-survival analysis of CHRNA5 in breast cancer untreated patient data, i.e., the survival cohort (datasets were obtained from KM plotter database). Positive effect size indicates a worse prognosis (high HR) and vice-versa. FEM: Fixed Effect Model; REM: Random Effect Model; TE: Treatment Effect. b Transcriptome-wide meta-correlation profile of

Enrichment of the E2F family in the CHRNA5 coexpressed module also points to the potential involvement of the E2F-RB pathway in the regulation of CHRNA5 expression. Mutational and/or transcriptional loss of $R B 1$ has been reported in $20 \%$ of basal breast cancers [46, 47]. Using the $E R$ cohort, we indeed found that $R B 1$ expression was downregulated in $\mathrm{ER}^{-}$breast cancer patients (REM: z-value: $-6.04, p=$ 1.5e-09; Supplementary Fig. 8a) and negatively correlated
CHRNA5 obtained from the survival cohort (i.e., each dot represents a meta-correlation score between each gene and CHRNA5 from all datasets of the survival cohort) along with the respective $\mathrm{ER}^{-} / \mathrm{ER}^{+}$effect sizes obtained from the ER cohort. Meta-HRs (survival cohort) are shown by color code. c Association statistics of genes highly correlated with CHRNA5 (absolute r.mean $>0.3$ ) with $\mathrm{ER}^{-} / \mathrm{ER}^{+}$effect size $(\mathrm{FDR}<$ $0.05)$ and meta-hazard ratio $(p<0.05)$ values indicated

with CHRNA5 ( $\mathrm{r}=-0.28, p=2.2 \mathrm{e}-20$; Supplementary Fig. 8b) as well as with E2F1 (r $=-0.43, p=9.7 \mathrm{e}-63$; Supplementary Fig. 8c). Consistently, TCGA CNA data analysis confirmed differential CNA frequencies of $R B 1$ between $\mathrm{ER}^{-}$and $\mathrm{ER}^{+}$breast tumors $\left(\chi^{2}=32.29, p<1 \mathrm{e}-5\right)$. In accordance with these results, CHRNA5 expression was higher in low RB1 expressing samples (Supplementary Fig. 8d). Using an independent ChIP-seq dataset, we confirmed the presence 
Table 1 Significantly regulated KEGG pathways of CHRNA5 coexpressed modules.

\begin{tabular}{cllll}
\hline \multirow{3}{*}{ Yellow (positive) } & Term & Count & P-value & Benjamini \\
& hsa04110:Cell cycle & 35 & $1.12 \mathrm{E}-29$ & $1.49 \mathrm{E}-27$ \\
& hsa03030:DNA replication & 17 & $3.05 \mathrm{E}-18$ & $2.03 \mathrm{E}-16$ \\
& hsa04115:p53 signaling pathway & 12 & $1.12 \mathrm{E}-07$ & $4.94 \mathrm{E}-06$ \\
& hsa04114:Oocyte meiosis & 13 & $2.53 \mathrm{E}-06$ & $8.40 \mathrm{E}-05$ \\
& hsa03430:Mismatch repair & 7 & $5.79 \mathrm{E}-06$ & $1.54 \mathrm{E}-04$ \\
& hsa00240:Pyrimidine metabolism & 12 & $9.96 \mathrm{E}-06$ & $2.21 \mathrm{E}-04$ \\
& hsa04914:Progesterone-mediated oocyte & 11 & $1.22 \mathrm{E}-05$ & $2.32 \mathrm{E}-04$ \\
maturation & & & \\
Turquoise & hsa03440:Homologous recombination & 6 & $3.00 \mathrm{E}-04$ & $4.98 \mathrm{E}-03$ \\
& hsa00230:Purine metabolism & 12 & $1.12 \mathrm{E}-03$ & $1.65 \mathrm{E}-02$ \\
& hsa03420:Nucleotide excision repair & 6 & $2.87 \mathrm{E}-03$ & $3.75 \mathrm{E}-02$ \\
& hsa04080:Neuroactive ligand-receptor interaction & 83 & $1.29 \mathrm{E}-23$ & $3.51 \mathrm{E}-21$ \\
& hsa05033:Nicotine addiction & 15 & $5.82 \mathrm{E}-06$ & $7.88 \mathrm{E}-04$ \\
& hsa04060:Cytokine-cytokine receptor interaction & 41 & $3.72 \mathrm{E}-05$ & $3.35 \mathrm{E}-03$ \\
& hsa05032:Morphine addiction & 22 & $4.95 \mathrm{E}-05$ & $3.35 \mathrm{E}-03$ \\
& hsa04723:Retrograde endocannabinoid signaling & 20 & $1.02 \mathrm{E}-03$ & $5.38 \mathrm{E}-02$ \\
& hsa04020:Calcium signaling pathway & 30 & $1.04 \mathrm{E}-03$ & $4.60 \mathrm{E}-02$ \\
& hsa04510:Focal adhesion & 16 & $5.44 \mathrm{E}-07$ & $9.80 \mathrm{E}-05$ \\
& hsa04512:ECM-receptor interaction & 11 & $7.87 \mathrm{E}-07$ & $7.08 \mathrm{E}-05$ \\
& hsa04151:PI3K-Akt signaling pathway & 17 & $7.37 \mathrm{E}-05$ & $4.41 \mathrm{E}-03$ \\
& hsa05200:Pathways in cancer & 18 & $1.02 \mathrm{E}-04$ & $4.58 \mathrm{E}-03$ \\
& hsa04142:Lysosome & 9 & $5.48 \mathrm{E}-04$ & $1.95 \mathrm{E}-02$ \\
hsa05146:Amoebiasis & 8 & $1.23 \mathrm{E}-03$ & $3.64 \mathrm{E}-02$ \\
\hline
\end{tabular}

of an E2F1 binding site in the CHRNA5 promoter with a binding capacity that seemed to directly increase with $R B 1$ knockdown (Supplementary Fig. 8e). These analyses indicate that CHRNA5 expression may be directly or indirectly regulated by E2F1 binding and/or loss of RB1.

\subsection{CHRNA5 co-expressed network is indirectly/secondarily regulated by E2 signaling}

An independent microarray dataset of E2 treatment in the presence or absence of CHX (GSE8597) was used to predict indirectly or secondarily induced targets by E2 using the PSscore such that the higher the PS-score value, the more secondarily induced the transcription was (algorithm details in methods). Including CHRNA5, we predicted a total of 367 such targets with PS-scores greater than $0.5(p<0.05)$. CHRNA5 having a high PS-score (0.87) suggested that it was indeed an E2-induced secondary target (Fig. 7a; Supplementary Table 6). Additionally, the top positively coexpressed module (yellow) was found to be highly enriched with these predicted secondary targets of E2 signaling (180 probesets from a total of 348 probesets in the module; Fig. 7b). In addition, these predicted secondarily induced targets were over-expressed in $\mathrm{ER}^{-}$breast cancers (Fig. 7c, e) and exhibited a worse prognosis (Fig. 7d, f). Our findings revealed that the more a gene was induced secondarily, i.e., PS-score $>0.5$, by E2 signaling and overexpressed in ER ${ }^{-}$breast tumors, the more hazardous it was as a prognostic biomarker $(\mathrm{r}=0.62$; $p=4.9 \mathrm{e}-41$; Fig. $7 \mathrm{~d}, \mathrm{f}$ ).

\subsection{CHRNA5 expression negatively correlates with that of primary ER targets}

We next mapped the ChIP-seq based list of primary ER interacting genes [36] onto our meta-analysis results (145 genes corresponding to jetset best probesets (GPL96)) and confirmed that unlike the predicted secondarily induced targets, more than half of the primary targets $(76 ; 52 \%)$ were significantly overexpressed $(\mathrm{FDR}<0.05)$ in $\mathrm{ER}^{+}$tumors while only $38(26 \%)$ were enriched in the $\mathrm{ER}^{-}$subtype (Supplementary Fig. 9a). In accordance with our previous findings, the expression of primary target genes enriched in $\mathrm{ER}^{+}$samples was negatively correlated with that of CHRNA5 (Supplementary Fig. 9a). Additionally, only nine genes out of 145 (including GREB1) overlapped between the predicted secondary targets and ChIP-seq retrieved primary targets (Supplementary Fig. 9b), demonstrating a low false positive rate and/or both primary as well as secondary targeting. We also investigated expression of these primary and secondary targets based on the TCGA breast cancer RNA-seq dataset. A 
Fig. 4 Distribution of metaanalysis scores in WGCNA CHRNA5 co-expression modules. a Six co-expression modules obtained from WGCNA using metacorrelated genes of the ER cohort (absolute r.mean $>0.2$ and $p<0.05)$. b Distribution of $\mathrm{ER}^{-}$ (effect-size $>0$ and FDR $<0.05$; ER cohort), $\mathrm{ER}^{+}$(effect-size $<0$ and FDR $<0.05 ;$ ER cohort) enriched and non-significant genes in CHRNA5 co-expressed modules. c Distribution of worse prognostic markers (Meta-HR $>0$ and $p<0.05$; survival cohort), good prognostic markers (Meta$\mathrm{HR}<0$ and $p<0.05$; survival cohort) and non-significant markers in CHRNA5 coexpression modules. After each bar, the mean CHRNA5 metacorrelation score of each module is shown to indicate positively and negatively correlated modules a

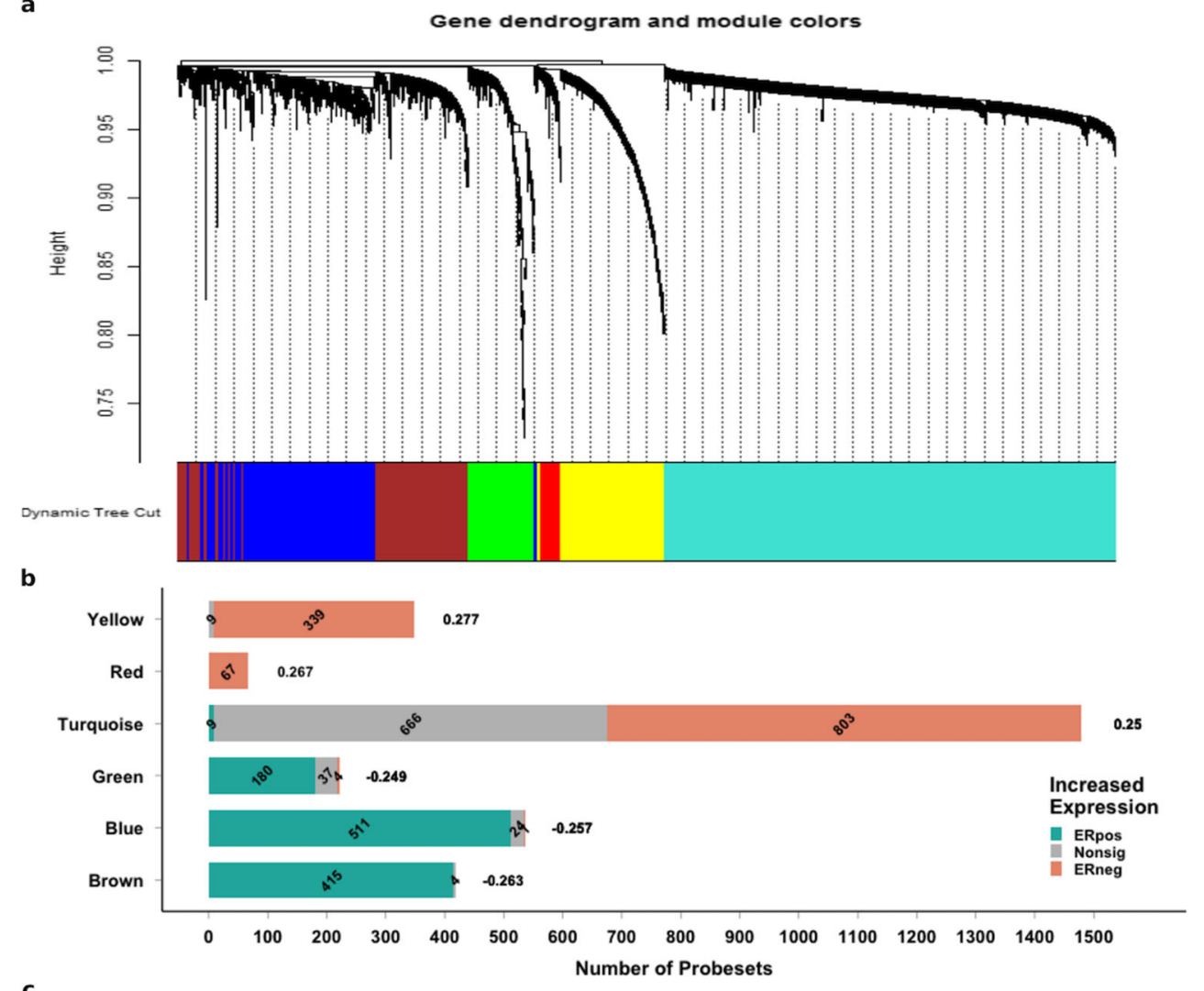

C

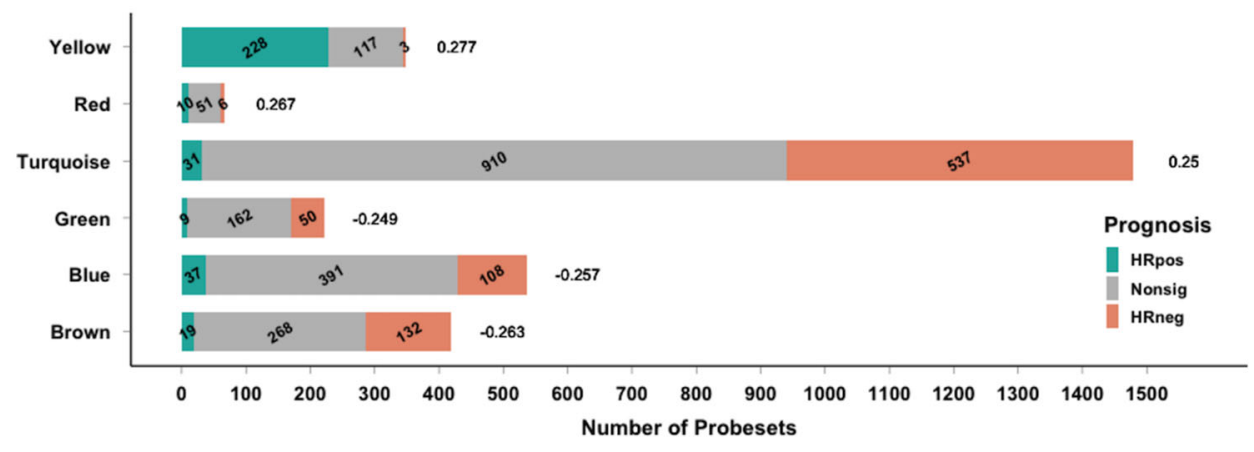

principal component analysis (PCA) plot of expression of primary targets and targets secondarily induced by E2 revealed the presence of two distinct clusters, with targets in the latter being more variably expressed (Fig. 8a). Primary and secondary targets were generally negatively correlated with each other based on a clustergram of TCGA data (Fig. $8 b)$. Overlaying of the meta-HR values on the PCA plot made the association between a worse prognosis and the secondary nature of E2 signaling more prominent. Retrospectively, higher expression of many primary targets was found to be associated with better survival outcomes (Fig. 8c).

\subsection{Comparison of CHRNA5 siRNA profile with E2- stimulation and hormone-starvation profiles}

We have previsouly shown that downregulation of CHRNA5 by RNAi in MCF7 cells results in increased apoptosis and reduced cell proliferation (GSE89333) [9]. However, the similarity between CHRNA5 depletion and E2-stimulation/starvation has not been studied yet. First, we confirmed that hormone starvation inversely modulated, while E2 exposure stimulated, the expression of CHRNA5 (Fig. 9a; GSE4668 [38]). Comparative transcriptomics performed between the 


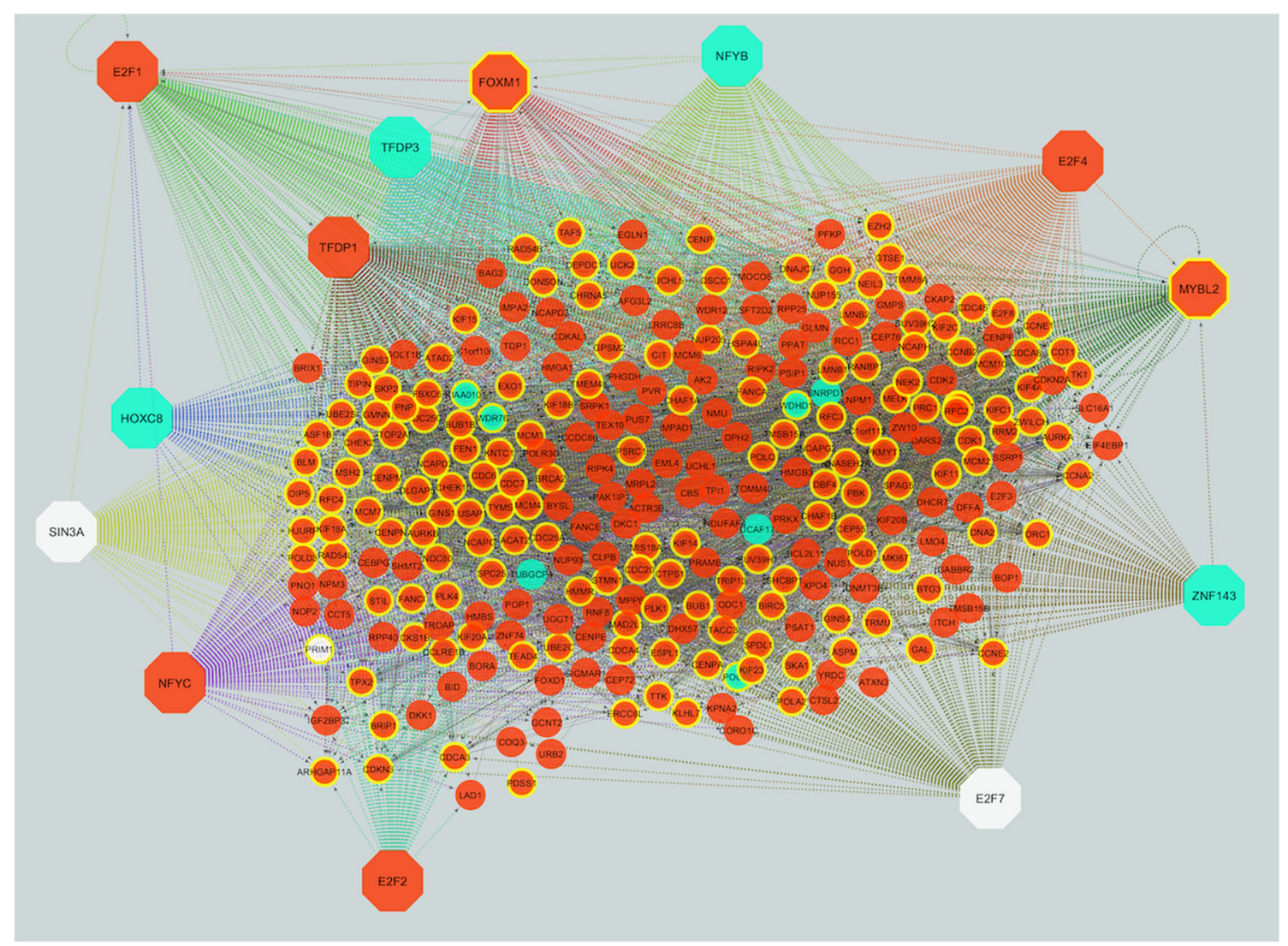

Fig. 5 Interaction network of the top positive CHRNA5 co-expressed network module (yellow) reveals targets of TF enrichment analysis. Octagonal nodes represent enriched TFs from IRegulon. Brown color indicates gene upregulation in $\mathrm{ER}^{-}$breast cancer patients and turquiuse color of nodes indicates gene upregulation in $\mathrm{ER}^{+}$breast cancer patients. White nodes represent either non-significant changes or unavailable probesets for genes. Yellow node borders indicate genes predicted to be E2-induced secondary targets based on PS-scores expression profiles showed a significantly negative correlation between CHRNA5 depletion and E2-stimulation response, while a positive one was observed between CHRNA5 depletion and hormone starvation (Fig. 9b-c) with highly significant Odds Ratios (ORs) (Fig. 9d). The results showed that knockdown of CHRNA5 in MCF7 cells partially mimicked hormone starvation-induced changes and negatively influenced E2-mediated transcriptomic regulation. Venndiagrams and KEGG enrichment of genes shared by all three conditions prioritized several pathways related with proliferation (Fig. 9e), as well as viral carcinogenesis and FoxO signaling (Fig. 9f).

Analysis of primary (direct) and secondary (indirect) E2induced targets in the context of these three expression profiles showed that the expression changes stratified according to the direction of PS-scores for the primary targets (Fig.10a). Interestingly, most ChIP-seq based gene probes [36] exhibiting positive PS-scores also had lower $\log \mathrm{FC}$ values, indicating downregulation both in the CHRNA5 depletion and E2-starvation profiles (Fig. 10a). Most of the predicted secondarily induced targets (PS-scores $>0.5$ by definition) were also significantly downregulated in both the CHRNA5 depleted and E2 starved MCF7 cells while being upregulated by E2 stimulation in general (Fig. 10b). LogFC values of the primary targets along with those of the secondarily induced targets could predict a significant portion of the variance across the meta-HR values (survival cohort) $\left(\mathrm{R}^{2}=0.37\right.$; Fig. 10c). We also overlayed the expression changes mediated by CHRNA5 depletion on the TCGA breast cancer dataset (Fig. 10d), further underscoring the degree of association between primary and secondary E2 signaling and CHRNA5 depletion. We were able to confirm the microarray-based expression changes for selected primary and secondary targets by RT-qPCR using CHRNA5 siRNA-treated MCF7 cells (Supplementary Table 4; Fig. 10e). In addition, we showed that there was dose as well as time dependency for CHRNA5 depletion, since the primary target effects decreased over time (72 h vs. $120 \mathrm{~h}$ ) and with increasing doses (lower vs. $50 \mathrm{nM}$ ) (Fig. 10e).

\section{Discussion}

Previously, the importance of the CHRNB4/A3/A5 locus in nicotine dependence and lung cancer has been reported [48]. Subsequently, several members of cholinergic receptors other 


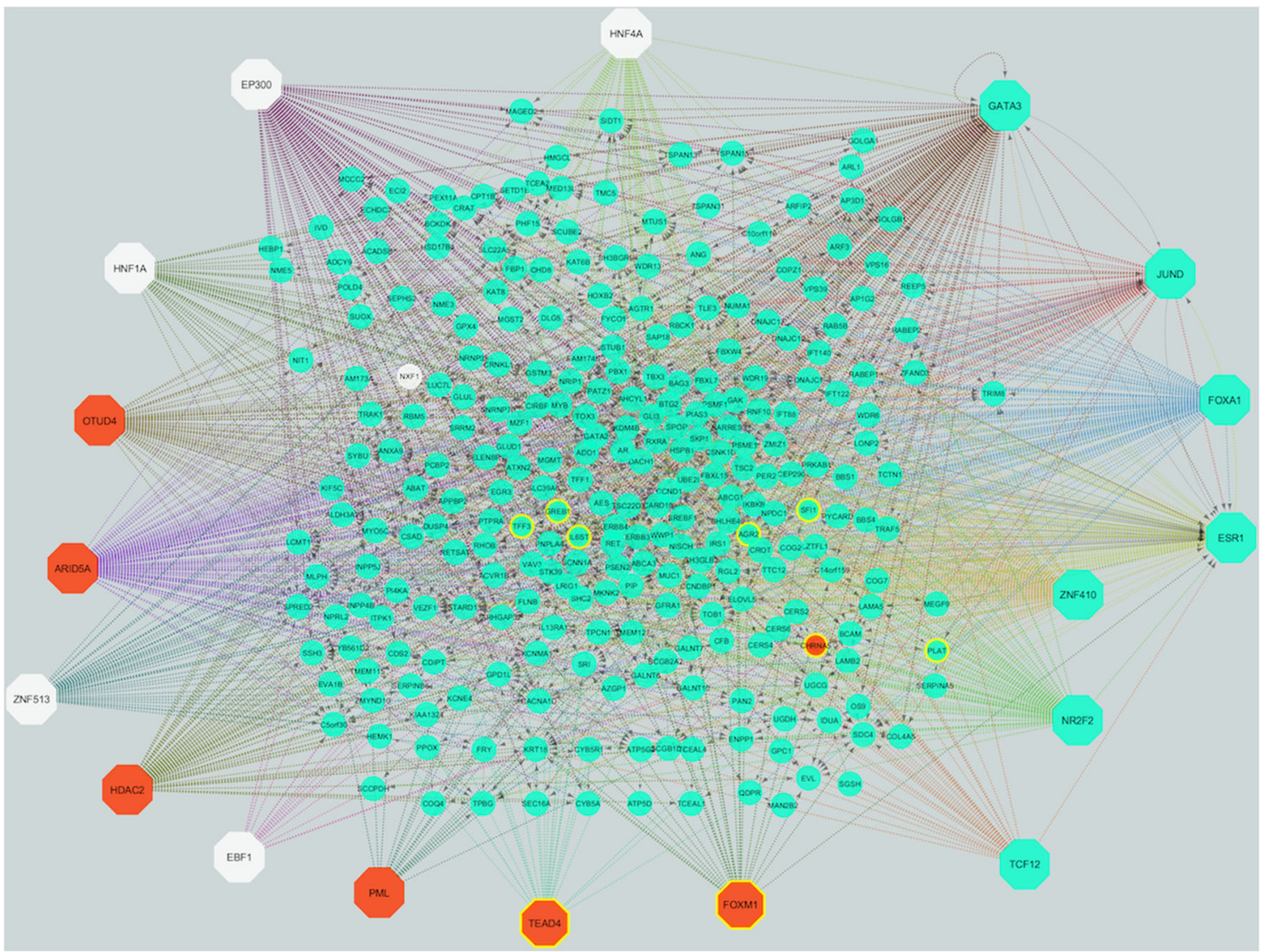

Fig. 6 Interaction network of the top negative CHRNA5 co-expression network module (brown) reveals targets of TF enrichment analysis. Octagonal nodes represent enriched TFs from IRegulon. Brown nodes indicate gene upregulation in $\mathrm{ER}^{-}$breast cancer patients and turquiuse nodes indicate gene upregulation in $\mathrm{ER}^{+}$breast cancer patients. White nodes represent either non-significant changes or unavailable data for genes. Yellow node borders indicate genes predicted to be secondary targets of E2 signaling according to PS-scores than CHRNA5 have been implicated in breast cancer and E2 signaling [6-8]. We previously revealed a role of CHRNA5 depletion by siRNA in cell cycle modulation, apoptosis and drug sensitivity in breast cancer cells [9]. Here, we provide a link between CHRNA5 expression and E2-mediated secondary signaling in breast cancer using meta-analysis, coexpression network and survival analyses, and RT-qPCR validation based on ex vivo and in vitro studies. Our results show that the expression of CHRNA5 may be modulated in breast cancer by $\mathrm{E} 2$ in cell line- and isoform-specific manners, while it exhibits a negative correlation with the expression of ESR1 in both cell lines and primary tumor samples. The observed decreased ESR1 expression upon E2 exposure is in accordance with the literature, since E2 exposure in breast cancer cells is known to lead to a feedback inhibition of ESR $1 \mathrm{mRNA}$ levels [48], which may be associated with increased CHRNA5 levels [49].

CHRNA5 isoforms, whose increased expression levels have been reported in the context of lung cancer [4], were also higher in breast tumors than normal tissues. CHRNA5 isoforms differ on the basis of alternative splicing in exon 5 (the trans-membrane domain of the protein) of the gene. The observed variability between CHRNA5 isoform expression in response to E2 in breast cancer cell lines and patient data may be explained by differential roles of the isoforms, since some (e.g., CHRNA5_V3) are implicated in impairment of signal transduction due to instability of the truncated transmembrane domain. The isoform-specific effects need to be further explored mechanistically in breast and other E2 responsive tissues. Use of an immunofluorescent antibody to track spatial distribution of different isoforms can help to distinguish between isoform-specific signal transduction patterns in cancer and normal cells.

In the present study we have also shown that CHRNA5 is induced by E2, secondarily. This novel finding is supported by (1) dependence of CHRNA5 expression changes on the duration of E2 exposure as well as the presence/absence of new protein synthesis [12] and (2) enrichment of the CHRNA5 co-expressed network with E2F transcription factors known to be directly or indirectly regulated by ESR1. Previously, E2F1induced genes have also been found to be more pronounced in $\mathrm{ER}^{-}$breast cancers and to be characterized by a worse prognostic potential, validating our findings [50,51]. Moreover, a recent study showed a positive association between E2F 
a

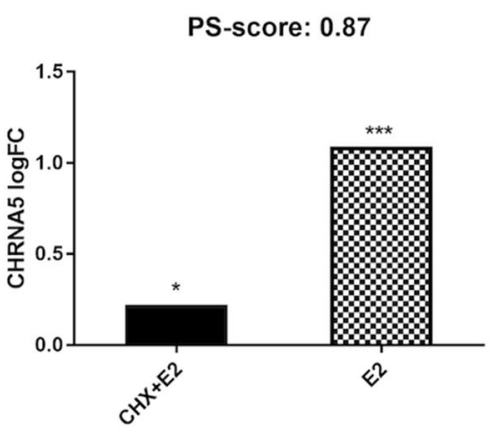

C

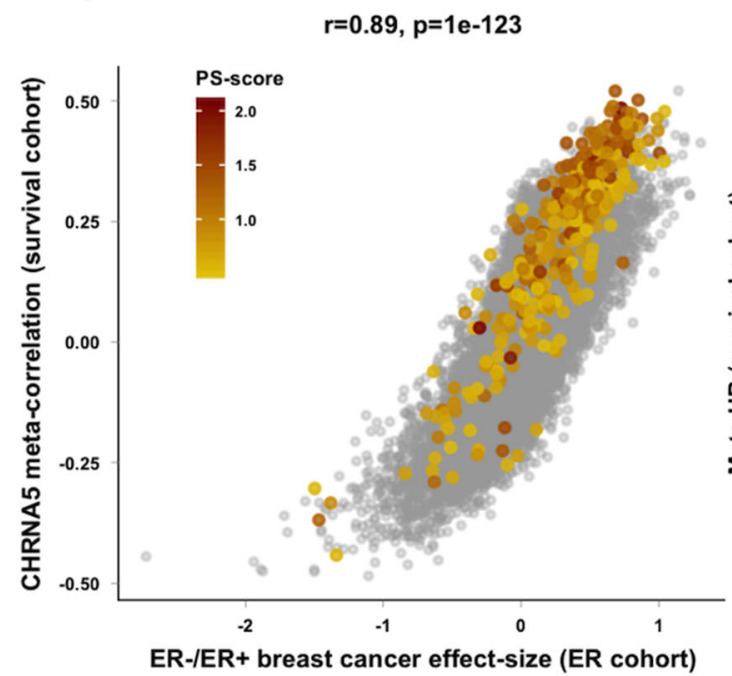

e

\begin{tabular}{|c|c|c|c|}
\hline \multirow{5}{*}{ 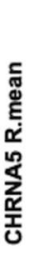 } & \multicolumn{3}{|c|}{ ER-/ER+ effect-size } \\
\hline & & Up & Down \\
\hline & Up & 259 & 5 \\
\hline & Down & 0 & 34 \\
\hline & P-value & \multicolumn{2}{|c|}{$9.06 \mathrm{E}-40$} \\
\hline
\end{tabular}

Fig. 7 CHRNA5 co-expression profile is enriched with secondary targets of E2 signaling. a CHRNA5 expression induced by E2 in the presence or absence of CHX (GSE8597). PS-scores were calculated as described in Materials and Methods. b Distribution of predicted E2-induced secondary targets in the CHRNA5 associated co-expression modules identified by WGCNA. c-d Mapping of the 366 other predicted E2-induced secondary

signaling and CHRNA5 expression in oral squamous cell carcinoma, while increased expression of the $E 2 F$ geneset and CHRNA5 was associated with a worse recurrence-free survival [52]. In addition to an E2F binding site enrichment, an inverse correlation between CRHNA5 and RB1 as well as downregulation of $R B 1$ in $\mathrm{ER}^{-}$breast cancers highlighted that dysregulation of RB1-E2F signaling may be responsible for CHRNA5 induction in $\mathrm{ER}^{-}$breast cancer. It is also known that ER-alpha cooperates with multiple TFs including SP1, NF-Y and c-FOS to mediate $E 2 F 1$ expresion in breast cancer cells $[53,54]$, and that $E 2 F 1$ expression is reduced by $\mathrm{E} 2$ starvation b

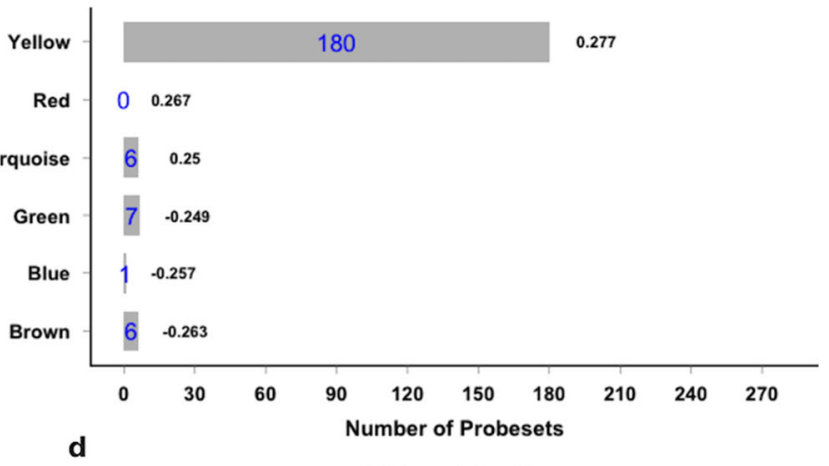

d

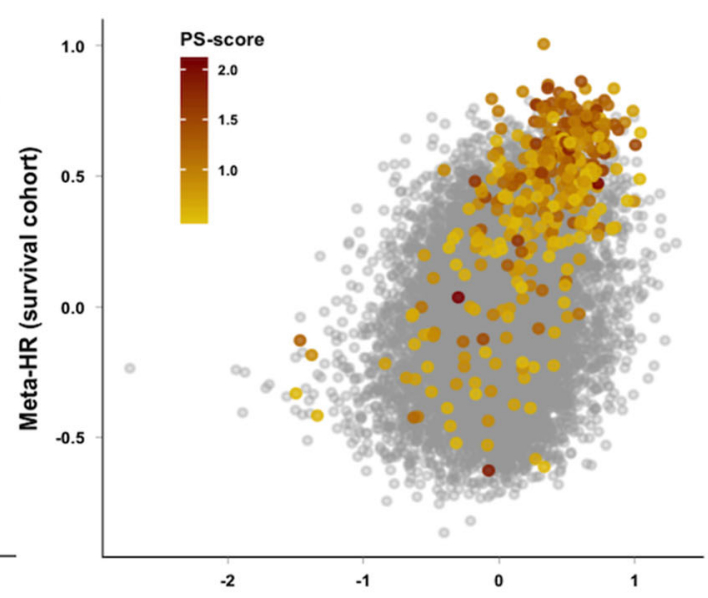

ER-/ER+ breast cancer effect-size (ER cohort)

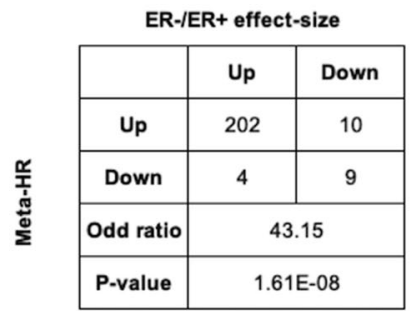

targets (by color code) on top of transcriptome-wide CHRNA5 correlations (from the survival cohort) and the differential $\mathrm{ER}^{-} / \mathrm{ER}^{+}$metaanalysis effect sizes (ER cohort) (c), and on top of transcriptome-wide HRs (survival cohort) and the differential ER meta-analysis (ER cohort) (d). e Contingency table and association statistics of $\mathbf{c}$. f Contingency table and association statistics of $\mathbf{d}$

$[38,55]$. However, further studies are needed to confirm any direct or indirect impact of the RB1-E2F1 signaling pathway on the modulation of CHRNA5 expression. Our findings indicate the importance of uncoupling cellular effects of primary and secondary targets of E2 signaling in breast tumors and implicate CHRNA5 depletion as a potential uncoupler of E2-driven ESR1 signaling (e.g., induction of primary target PGR [56], and depletion of secondary target CDC6 [57]).

The prominent expression of some E2-induced targets in the $\mathrm{ER}^{-}$breast cancers may also point to alternative mechanisms driven by factors other than ESR1. Indeed, close to 
a

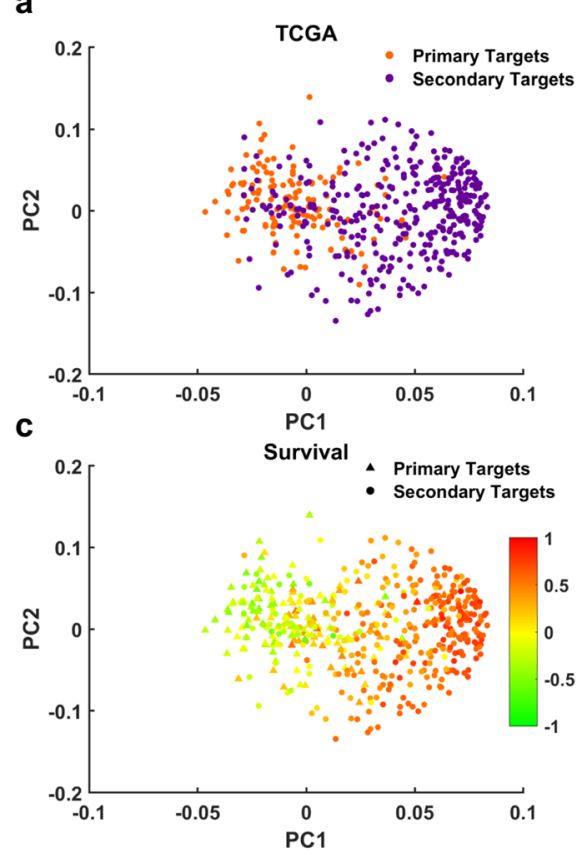

Fig. 8 ChIP-defined ESR1 primary targets and E2-induced secondary targets are clustered distinctly based on TCGA breast cancer RNA-seq data. a Principal component analysis (PCA) plot of primary (orange) and secondary (purple) target gene expression data from TCGA. b

half of breast cancer patients express ESR1, but almost $60 \%$ of the $\mathrm{ER}^{-}$cases are reported to be positive for ESR2 (ERbeta receptor). ESR2 may exert its effects ligand-independently, for example, via microRNAs [58, 59]. ESR2 has also been shown to mediate responses to tamoxifen in $\mathrm{ER}^{-}$breast cancer patients by interacting with TP53 [60-62]. GPER1, known to interact with E2, is yet another candidate receptor that may be highly expressed in $\mathrm{ER}^{-}$ breast cancer patients [63, 64]. Additionally, unliganded ESR1 can be constitutionally active due to mutations that can be found in the E2 binding site [43, 65, 66]. Steroid receptor coactivators have also been shown to mediate E2dependent effects in breast cancer [67]. Hence, E2 may act through these alternative pathways and modify the genomic and non-genomic actions of ESR1. Moreover, CHRNA9, which is a cholinergic receptor with a higher expression in $\mathrm{ER}^{+}$tumors and known to form heteromeres with CHRNA5 subunits, can play modulatory roles in E2-mediated actions of ERs through phosphorylation events [7]. On the other hand, when the expression of CHRNA9 was silenced along with that of CHRNA5 in $\mathrm{ER}^{-}$MDA-MB-231 cells, they could not survive, suggesting a complex interplay between these two receptors [8]. Therefore, future studies should focus on isogenic cell lines with and without receptors interacting with E2 and/or acetylcholine to mechanistically decipher the crosstalk between ERs and cholinergic receptor subunits.
Nicotinic acetylcholine receptor (nAChR) modulators have shown potential in reducing tumor growth by targeting different subunits of the pentameric complex. Alpha-neurotoxins (from snake venom) are potential anti-tumor drugs that affect cell proliferation by regulating the expression of CHRNA7 in non-small cell lung carcinoma [68]. Natural anti-nicotinic ligands (SLURP-1/SLURP-2) in combination with nicotinic receptor antagonists (mecamylamine, luteoline or methyllycaconitine) have been found to exhibit effects on cell viability and cancer therapeutics by regulating the expression of CHRNA7 or CHRNA9 [69]. Conotoxins and $\alpha$-cobratoxin (MII, PnIA, RgIA and ArIB11L16D) have been reported to potentially target and inhibit different $\mathrm{nAChR}$ subunits $(\alpha 6$, $\alpha 3 \beta 2, \alpha 9 \alpha 10$ and $\alpha 7 \mathrm{nAChRs}$ ) and, consequently, slow down tumor progression and inflammation in a mouse model $[70,71]$. To the best of our knowledge, however, no specific CHRNA5 inhibitor has been studied for its anti-tumor activity. This, therefore, warrants further development and exploration.

Our study revealed a significantly linear and positive correlation between the values of prognostic indicators and PSscores describing the direction and magnitude of primary and secondary expression modulations by E2. Accordingly, the majority of primary targets are associated with a better prognosis (meta-HR values $<0$ ) while secondary targets exhibit higher meta-HRs. The magnitude and direction of PS-scores can help to predict the prognostic role of a gene in breast 
a

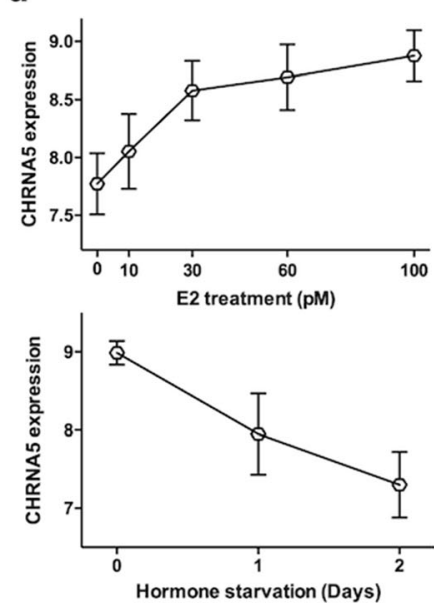

d

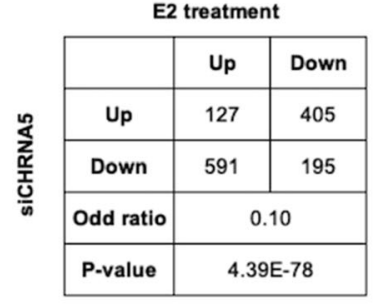

Starvation

\begin{tabular}{|c|c|c|}
\hline & Up & Down \\
\hline Up & 527 & 57 \\
\hline Down & 246 & 589 \\
\hline Odd ratio & \multicolumn{2}{|c|}{22.07} \\
\hline P-value & \multicolumn{2}{|c|}{$2.81 E-125$} \\
\hline
\end{tabular}

Fig. 9 CHRNA5 depletion profile resembles hormone starvation profile and downregulates proliferative pathways. a Change in CHRNA5 probeset expression in E2-treated (across increasing doses) and -starved MCF7 microarray datasets (across time). b-c Comparison of CHRNA5 knockdown mediated transcriptomic changes with E2-treated (b), and hormone-starved log fold changes (c) where significant genes in both datasets $(p<0.05)$ are labeled blue while non-significant regulation in

e
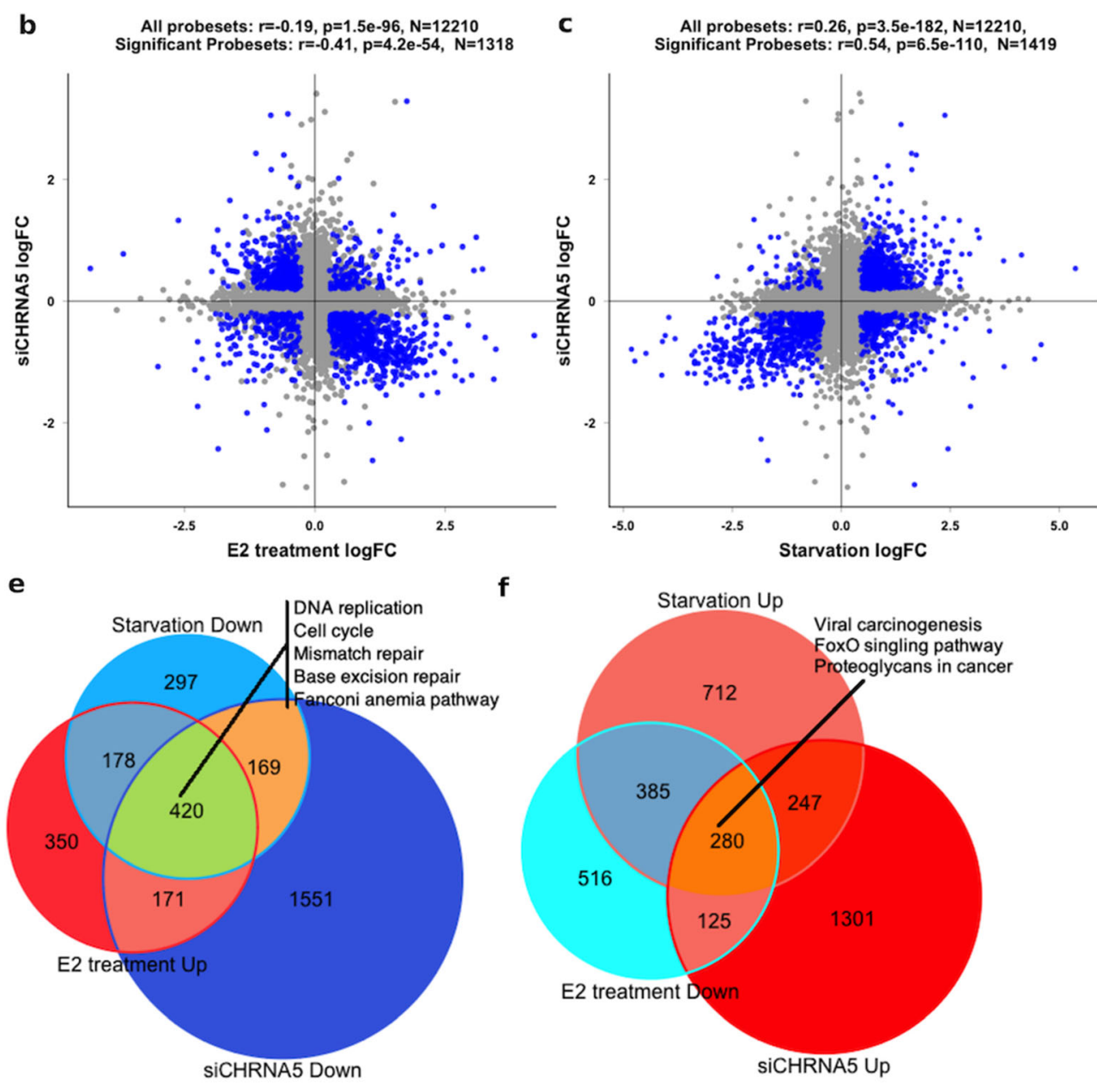

either of the dataset is shown in grey. $\mathbf{d}$ Contingency table and association statistics of significantly regulated genes shown in $\mathbf{b}$ and $\mathbf{c}$. e-f Shared regulated genes downregulated by CHRNA5 knockdown and E2starvation profile while upregulated by E2 treatment (e), and vice-versa (f). Top 5 pathways from KEGG pathway enrichment analysis with FDR $<0.05$ are marked

cancer, and in the future these can be tested in other cancers where E2 plays a role. As a result, CHRNA5 depletion downregulates most of the targets induced secondarily by E2 stimulation while the primary targets of ESR1, identified by ChIP-seq, can be induced or repressed, as partially predicted by their PS-scores. Our analysis of the TCGA breast cancer data supports this uncoupling via demonstrating a negative correlation between primary and secondary target expression profiles. However, it is important to note that some targets bound by ESR1 upon E2 stimulation (e.g., MYLB1 and DTL, Fig. 10e) can also be targeted secondarily. In such cases, PS-scores help to predict the prognostic significance better than ChIP-seq results alone.

Previously, microarray-based meta-analyses have focused on either expression profiles of E2 treated cells [13, 72], differential gene expression in breast cancer subtypes [73-75], or the prognostic importance of a gene or geneset in breast cancer [25]. In the present study, we have combined all three types of meta-analyses to address the involvement of CHRNA5 and its co-expression network in breast cancer prognosis. We have also confirmed our predictions using different independent cohorts, e.g., COSMIC and CCLE data in case of cell lines and TCGA RNA-seq data in case of patient samples, validation by RT-qPCR using five different breast cancer cell lines, CHRNA5 siRNA or control siRNA treated MCF7 cells, and across independent patient cDNA samples. Our study presents CHRNA5 as a potential biomarker, whose expression can be targeted in breast cancer in a subtype-specific manner to obtain a better breast cancer prognostication. Our study has highlighted a novel association between CHRNA5 expression and the RB1-E2F1 pathway. Future studies are needed to identify the underlying mechanisms and to open up novel 
a

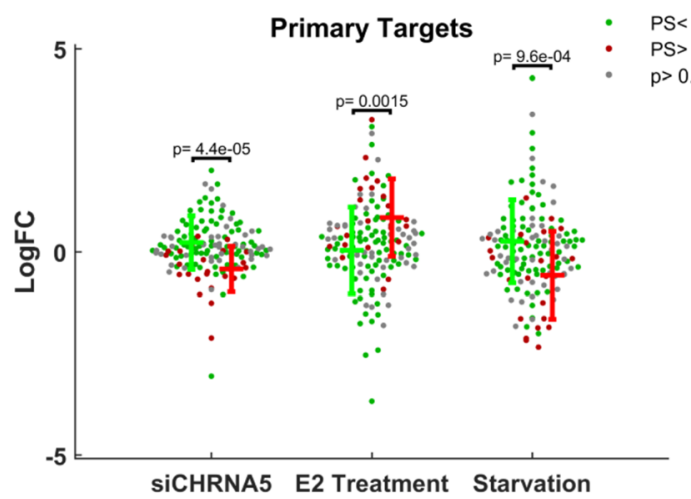

C

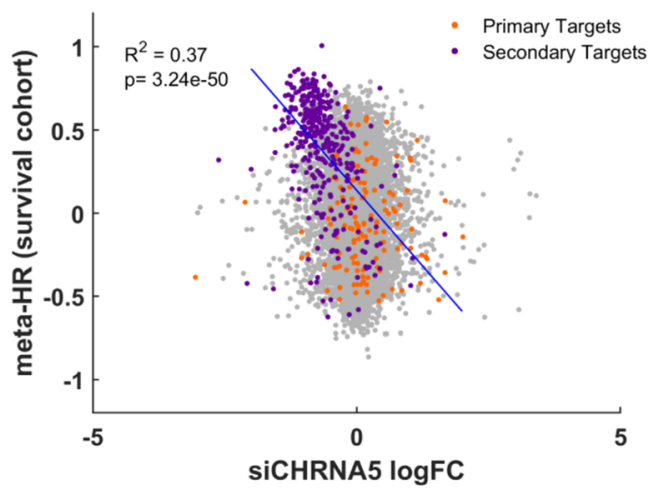

b

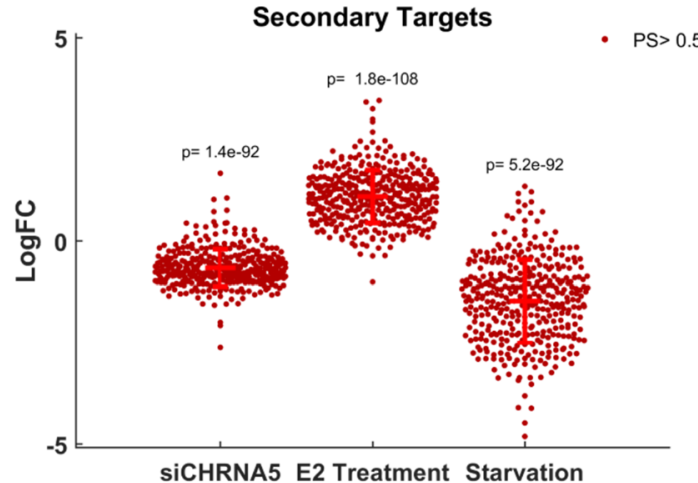

siCHRNA5 E2 Treatment Starvation

d

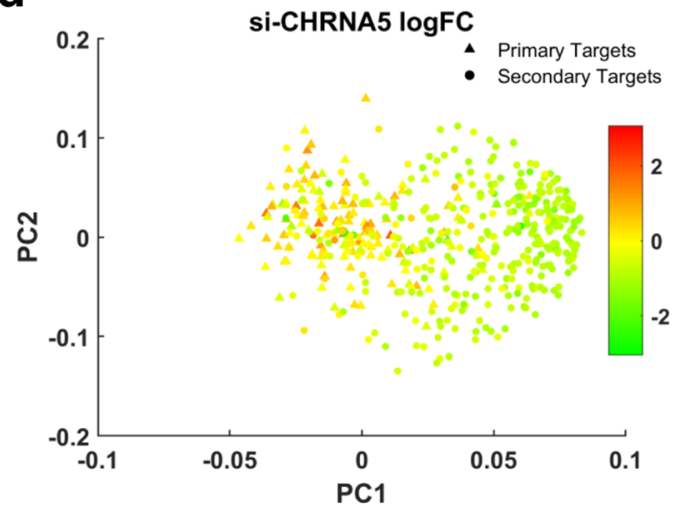

e

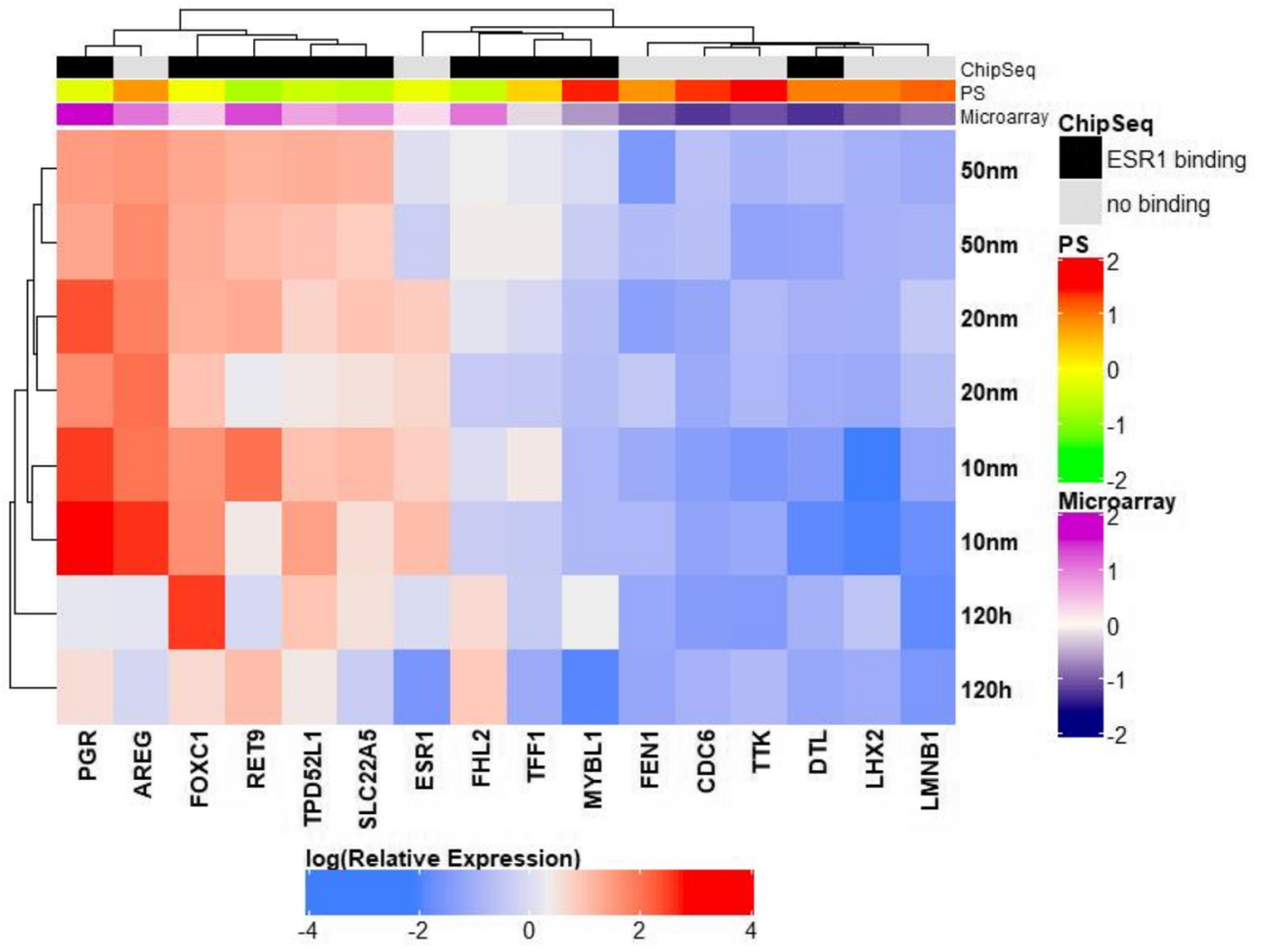


Fig. 10 Primary and secondary targets are differentially modulated by CHRNA5 siRNA, E2-treatment and hormone starvation. a-b Change in the ESR1 primary targets (a) and predicted secondary targets (PS $>0.5$ and $p<0.05)(\mathbf{b})$, in response to CHRNA5 siRNA treatment, E2treatment and -starvation; $p$-values from student's t test are reported on top of each comparison. $\mathbf{c}$ Mapping of the primary (orange) and predicted secondary (purple) targets on top of mHR scores (from the survival cohort) and the siCHRNA5 transcriptome. d Mapping of $\operatorname{logFC}$ values from si-CHRNA5 profile on top of principal component analysis (PCA) plot of primary and secondary target gene expression data from TCGA. e RT-qPCR validation of expression changes in selected primary and secondary targets in si-CHRNA5 treated MCF7 cells in a time- and dosedependent manner

therapeutic avenues. The list of E2-induced secondary targets found in the CHRNA5 co-expression network, and the significant association with PS-score, CHRNA5 depletion response and prognostic outcome may be of help to better understand the outcome of E2 signaling in breast tumors. Finally, our findings suggest that precise stratification of expression of primary and secondary targets of E2 signaling may help to better predict the prognostic outcome.

Supplementary Information The online version contains supplementary material available at https://doi.org/10.1007/s13402-020-00581-x.

Acknowledgments This study was funded by a research grant from The Scientific and Technological Research Council of Turkey (to OK; TUBITAK, 111 T316). We are thankful to the Higher Education Commission (HEC), Pakistan for funding Huma Shehwana for her $\mathrm{PhD}$ studies. We thank TUBITAK for financial assistance to Emine Sila Ozdemir during her Master studies (Scholarship 2210-E). We also thank Can Alkan and Marzieh Eslami Rasekh for helping us with the computation power needed to process microarray files.

\section{Compliance with ethical standards}

Conflict of interest The authors declare that they have no conflict of interest.

\section{References}

1. T. Truong, R.J. Hung, C.I. Amos, X. Wu, H. Bickeboller, A. Rosenberger, W. Sauter, T. Illig, H.E. Wichmann, A. Risch, H. Dienemann, R. Kaaks, P. Yang, R. Jiang, J.K. Wiencke, M. Wrensch, H. Hansen, K.T. Kelsey, K. Matsuo, K. Tajima, A.G. Schwartz, A. Wenzlaff, A. Seow, C. Ying, A. Staratschek-Jox, P. Nurnberg, E. Stoelben, J. Wolf, P. Lazarus, J.E. Muscat, C.J. Gallagher, S. Zienolddiny, A. Haugen, H.F. van der Heijden, L.A. Kiemeney, D. Isla, J.I. Mayordomo, T. Rafnar, K. Stefansson, Z.F. Zhang, S.C. Chang, J.H. Kim, Y.C. Hong, E.J. Duell, A.S. Andrew, F. Lejbkowicz, G. Rennert, H. Muller, H. Brenner, L. Le Marchand, S. Benhamou, C. Bouchardy, M.D. Teare, X. Xue, J. McLaughlin, G. Liu, J.D. McKay, P. Brennan, M.R. Spitz, Replication of lung cancer susceptibility loci at chromosomes $15 \mathrm{q} 25,5 \mathrm{p} 15$, and $6 \mathrm{p} 21$ : a pooled analysis from the International Lung Cancer Consortium. J Natl Cancer Inst 102, 959-971 (2010). https://doi.org/10.1093/jnci/djq178
2. F.S. Falvella, A. Galvan, E. Frullanti, M. Spinola, E. Calabro, A. Carbone, M. Incarbone, L. Santambrogio, U. Pastorino, T.A. Dragani, Transcription deregulation at the $15 \mathrm{q} 25$ locus in association with lung adenocarcinoma risk. Clin Cancer Res 15, 1837 1842 (2009). https://doi.org/10.1158/1078-0432.CCR-08-2107

3. S.S. Yoo, S.M. Lee, S.K. Do, W.K. Lee, D.S. Kim, J.Y. Park, Unmethylation of the CHRNB4 gene is an unfavorable prognostic factor in non-small cell lung cancer. Lung Cancer 86, 85-90 (2014). https://doi.org/10.1016/j.lungcan.2014.08.002

4. F.S. Falvella, T. Alberio, S. Noci, L. Santambrogio, M. Nosotti, M. Incarbone, U. Pastorino, M. Fasano, T.A. Dragani, Multiple isoforms and differential allelic expression of CHRNA5 in lung tissue and lung adenocarcinoma. Carcinogenesis 34, 1281-1285 (2013). https://doi.org/10.1093/carcin/bgt062

5. C.C. Warzecha, S. Shen, Y. Xing, R.P. Carstens, The epithelial splicing factors ESRP1 and ESRP2 positively and negatively regulate diverse types of alternative splicing events. RNA Biol 6, 546$562(2009)$

6. Q. Xu, T. Hamada, R. Kiyama, Y. Sakuma, Y. Wada-Kiyama, Sitespecific regulation of gene expression by estrogen in the hypothalamus of adult female rats. Neurosci Lett 436, 35-39 (2008). https:// doi.org/10.1016/j.neulet.2008.02.054

7. C.H. Lee, Y.C. Chang, C.S. Chen, S.H. Tu, Y.J. Wang, L.C. Chen, Y.J. Chang, P.L. Wei, H.W. Chang, C.H. Chang, C.S. Huang, C.H. $\mathrm{Wu}$, Y.S. Ho, Crosstalk between nicotine and estrogen-induced estrogen receptor activation induces alpha9-nicotinic acetylcholine receptor expression in human breast cancer cells. Breast Cancer Res Treat 129, 331-345 (2011)

8. C.H. Lee, C.S. Huang, C.S. Chen, S.H. Tu, Y.J. Wang, Y.J. Chang, K.W. Tam, P.L. Wei, T.C. Cheng, J.S. Chu, L.C. Chen, C.H. Wu, Y.S. Ho, Overexpression and activation of the alpha9-nicotinic receptor during tumorigenesis in human breast epithelial cells. J Natl Cancer Inst 102, 1322-1335 (2010). https://doi.org/10.1093/jnci/ djq300

9. S. Cingir Koker, E. Jahja, H. Shehwana, A.G. Keskus, O. Konu, Cholinergic receptor nicotinic alpha 5 (CHRNA5) RNAi is associated with cell cycle inhibition, apoptosis. DNA damage response and drug sensitivity in breast cancer PLoS One 13, e0208982 (2018). https://doi.org/10.1371/journal.pone.0208982

10. M.R. Meyer, E. Haas, E.R. Prossnitz, M. Barton, Non-genomic regulation of vascular cell function and growth by estrogen. Mol Cell Endocrinol 308, 9-16 (2009). https://doi.org/10.1016/j.mce. 2009.03.009

11. J. Frasor, J.M. Danes, B. Komm, K.C. Chang, C.R. Lyttle, B.S. Katzenellenbogen, Profiling of estrogen up- and down-regulated gene expression in human breast cancer cells: Insights into gene networks and pathways underlying estrogenic control of proliferation and cell phenotype. Endocrinology 144, 4562-4574 (2003). https://doi.org/10.1210/en.2003-0567

12. V. Bourdeau, J. Deschenes, D. Laperriere, M. Aid, J.H. White, S. Mader, Mechanisms of primary and secondary estrogen target gene regulation in breast cancer cells. Nucleic Acids Res 36, 76-93 (2008). https://doi.org/10.1093/nar/gkm945

13. V. Jagannathan, M. Robinson-Rechavi, Meta-analysis of estrogen response in MCF-7 distinguishes early target genes involved in signaling and cell proliferation from later target genes involved in cell cycle and DNA repair. BMC Syst Biol 5, 138 (2011). https:// doi.org/10.1186/1752-0509-5-138

14. B.K. Banin Hirata, J.M. Oda, R. Losi Guembarovski, C.B. Ariza, C.E. de Oliveira, M.A. Watanabe, Molecular markers for breast cancer: Prediction on tumor behavior. Dis Markers 2014, 513158-513112 (2014). https://doi.org/10.1155/2014/513158

15. E.R. Prossnitz, M. Maggiolini, Mechanisms of estrogen signaling and gene expression via GPR30. Mol Cell Endocrinol 308, 32-38 (2009). https://doi.org/10.1016/j.mce.2009.03.026 
16. B. Haibe-Kains, C. Desmedt, F. Piette, M. Buyse, F. Cardoso, L. Van't Veer, M. Piccart, G. Bontempi, C. Sotiriou, Comparison of prognostic gene expression signatures for breast cancer. BMC Genomics 9, 394 (2008). https://doi.org/10.1186/1471-2164-9-394

17. E.K. Millar, P.H. Graham, S.A. O'Toole, C.M. McNeil, L. Browne, A.L. Morey, S. Eggleton, J. Beretov, C. Theocharous, A. Capp, E. Nasser, J.H. Kearsley, G. Delaney, G. Papadatos, C. Fox, R.L. Sutherland, Prediction of local recurrence, distant metastases, and death after breast-conserving therapy in early-stage invasive breast cancer using a five-biomarker panel. J Clin Oncol 27, 4701-4708 (2009). https://doi.org/10.1200/JCO.2008.21.7075

18. M.L. Salmans, F. Zhao, B. Andersen, The estrogen-regulated anterior gradient 2 (AGR2) protein in breast cancer: A potential drug target and biomarker. Breast Cancer Res 15, 204 (2013). https://doi. org/10.1186/bcr3408

19. D.S. Oh, M.A. Troester, J. Usary, Z. Hu, X. He, C. Fan, J. Wu, L.A. Carey, C.M. Perou, Estrogen-regulated genes predict survival in hormone receptor-positive breast cancers. J Clin Oncol 24, 16561664 (2006). https://doi.org/10.1200/JCO.2005.03.2755

20. R. Kumar, A. Sharma, R.K. Tiwari, Application of microarray in breast cancer: An overview. J Pharm Bioallied Sci 4, 21-26 (2012). https://doi.org/10.4103/0975-7406.92726

21. B.J. Trock, F. Leonessa, R. Clarke, Multidrug resistance in breast cancer: A meta-analysis of MDR1/gp170 expression and its possible functional significance. J Natl Cancer Inst 89, 917-931 (1997)

22. Y. Pawitan, J. Bjohle, L. Amler, A.L. Borg, S. Egyhazi, P. Hall, X. Han, L. Holmberg, F. Huang, S. Klaar, E.T. Liu, L. Miller, H. Nordgren, A. Ploner, K. Sandelin, P.M. Shaw, J. Smeds, L. Skoog, S. Wedren, J. Bergh, Gene expression profiling spares early breast cancer patients from adjuvant therapy: Derived and validated in two population-based cohorts. Breast Cancer Res 7, R953-R964 (2005). https://doi.org/10.1186/bcr1325

23. T. Barrett, D.B. Troup, S.E. Wilhite, P. Ledoux, C. Evangelista, I.F. Kim, M. Tomashevsky, K.A. Marshall, K.H. Phillippy, P.M. Sherman, R.N. Muertter, M. Holko, O. Ayanbule, A. Yefanov, A. Soboleva, NCBI GEO: Archive for functional genomics data sets10 years on. Nucleic Acids Res 39, D1005-D1010 (2011). https:// doi.org/10.1093/nar/gkq1184

24. R. Edgar, M. Domrachev, A.E. Lash, Gene expression omnibus: NCBI gene expression and hybridization array data repository. Nucleic Acids Res 30, 207-210 (2002)

25. B. Gyorffy, A. Lanczky, A.C. Eklund, C. Denkert, J. Budczies, Q. $\mathrm{Li}, \mathrm{Z}$. Szallasi, An online survival analysis tool to rapidly assess the effect of 22,277 genes on breast cancer prognosis using microarray data of 1,809 patients. Breast Cancer Res Treat 123, 725-731 (2010). https://doi.org/10.1007/s10549-009-0674-9

26. X. Wang, D.D. Kang, K. Shen, C. Song, S. Lu, L.C. Chang, S.G. Liao, Z. Huo, S. Tang, Y. Ding, N. Kaminski, E. Sibille, Y. Lin, J. Li, G.C. Tseng, An R package suite for microarray meta-analysis in quality control, differentially expressed gene analysis and pathway enrichment detection. Bioinformatics 28, 2534-2536 (2012). https://doi.org/10.1093/bioinformatics/bts485

27. G. Schwarzer, metacor: General package for meta-analysis (2016)

28. E. Laliberté, metacor: Meta-analysis of correlation coefficients (2011)

29. P. Langfelder, S. Horvath, WGCNA: An R package for weighted correlation network analysis. BMC Bioinformatics 9, 559 (2008). https://doi.org/10.1186/1471-2105-9-559

30. P. Shannon, A. Markiel, O. Ozier, N.S. Baliga, J.T. Wang, D. Ramage, N. Amin, B. Schwikowski, T. Ideker, Cytoscape: A software environment for integrated models of biomolecular interaction networks. Genome Res 13, 2498-2504 (2003). https://doi.org/10. $1101 /$ gr. 1239303

31. A. Franceschini, D. Szklarczyk, S. Frankild, M. Kuhn, M. Simonovic, A. Roth, J. Lin, P. Minguez, P. Bork, C. von Mering, L.J. Jensen, STRING v9.1: protein-protein interaction networks, with increased coverage and integration. Nucleic Acids Res. 41, D808-D815 (2013). https://doi.org/10.1093/nar/gks1094

32. R. Janky, A. Verfaillie, H. Imrichova, B. Van de Sande, L. Standaert, V. Christiaens, G. Hulselmans, K. Herten, M. Naval Sanchez, D. Potier, D. Svetlichnyy, Z. Kalender Atak, M. Fiers, J.C. Marine, S. Aerts, iRegulon: From a gene list to a gene regulatory network using large motif and track collections. PLoS Comput Biol 10, e1003731 (2014). https://doi.org/10.1371/journal.pcbi. 1003731

33. W. da Huang, B.T. Sherman, R.A. Lempicki, Systematic and integrative analysis of large gene lists using DAVID bioinformatics resources. Nat Protoc 4, 44-57 (2009). https://doi.org/10.1038/ nprot.2008.211

34. A.D. Rouillard, G.W. Gundersen, N.F. Fernandez, Z. Wang, C.D. Monteiro, M.G. McDermott, A. Ma'ayan, The harmonizome: A collection of processed datasets gathered to serve and mine knowledge about genes and proteins. Database (Oxford) 2016 (2016). https://doi.org/10.1093/database/baw100

35. E. Cerami, J. Gao, U. Dogrusoz, B.E. Gross, S.O. Sumer, B.A. Aksoy, A. Jacobsen, C.J. Byrne, M.L. Heuer, E. Larsson, Y. Antipin, B. Reva, A.P. Goldberg, C. Sander, N. Schultz, The cBio cancer genomics portal: An open platform for exploring multidimensional cancer genomics data. Cancer Discov 2, 401-404 (2012). https://doi.org/10.1158/2159-8290.CD-12-0095

36. M. Jia, T. Andreassen, L. Jensen, T.F. Bathen, I. Sinha, H. Gao, C. Zhao, L.A. Haldosen, Y. Cao, L. Girnita, S.A. Moestue, K. Dahlman-Wright, Estrogen receptor alpha promotes breast cancer by reprogramming choline metabolism. Cancer Res 76, 5634-5646 (2016). https://doi.org/10.1158/0008-5472.CAN-15-2910

37. Q. Li, N.J. Birkbak, B. Gyorffy, Z. Szallasi, A.C. Eklund, Jetset: Selecting the optimal microarray probe set to represent a gene. BMC Bioinformatics 12, 474 (2011). https://doi.org/10.1186/ 1471-2105-12-474

38. K.R. Coser, J. Chesnes, J. Hur, S. Ray, K.J. Isselbacher, T. Shioda, Global analysis of ligand sensitivity of estrogen inducible and suppressible genes in MCF7/BUS breast cancer cells by DNA microarray. Proc Natl Acad Sci U S A 100, 13994-13999 (2003). https:// doi.org/10.1073/pnas.2235866100

39. E. Guivarc'h, M. Buscato, A.L. Guihot, J. Favre, E. Vessieres, L. Grimaud, J. Wakim, N.J. Melhem, R. Zahreddine, M. Adlanmerini, Predominant role of nuclear versus membrane estrogen receptor $\alpha$ in arterial protection: Implications for estrogen receptor $\alpha$ modulation in cardiovascular prevention/safety. J Am Heart Assoc 7, e008950 (2018)

40. J. Fu, L. Bian, L. Zhao, Z. Dong, X. Gao, H. Luan, Y. Sun, H. Song, Identification of genes for normalization of quantitative real-time PCR data in ovarian tissues. Acta Biochim Biophys Sin 42, 568574 (2010)

41. K. Stokes, B. Alston-Mills, C. Teng, Estrogen response element and the promoter context of the human and mouse lactoferrin genes influence estrogen receptor $\alpha$-mediated transactivation activity in mammary gland cells. J Mol Endocrinol 33, 315-334 (2004)

42. B.H. Akman, T. Can, A.E. Erson-Bensan, Estrogen-induced upregulation and 3'-UTR shortening of CDC6. Nucleic Acids Res 40, 10679-10688 (2012). https://doi.org/10.1093/nar/gks855

43. H. Alotaibi, E.C. Yaman, E. Demirpençe, U.H. Tazebay, Unliganded estrogen receptor- $\alpha$ activates transcription of the mammary gland $\mathrm{Na}+/ \mathrm{I}-$ symporter gene. Biochem Biophys Res Commun 345, 1487-1496 (2006)

44. K.J. Livak, T.D. Schmittgen, Analysis of relative gene expression data using real-time quantitative PCR and the $2-\Delta \Delta \mathrm{CT}$ method. Methods 25, 402-408 (2001)

45. A. Bahreini, Z. Li, P. Wang, K.M. Levine, N. Tasdemir, L. Cao, H.M. Weir, S.L. Puhalla, N.E. Davidson, A.M. Stern, D. Chu, B.H. Park, A.V. Lee, S. Oesterreich, Mutation site and context dependent effects of ESR1 mutation in genome-edited breast cancer cell 
models. Breast Cancer Res 19, 60-60 (2017). https://doi.org/10. 1186/s13058-017-0851-4

46. D.C. Koboldt, R.S. Fulton, M.D. McLellan, H. Schmidt, J. KalickiVeizer, J.F. McMichael, L.L. Fulton, D.J. Dooling, L. Ding, E.R. Mardis, R.K. Wilson, A. Ally, M. Balasundaram, Y.S.N. Butterfield, R. Carlsen, C. Carter, A. Chu, E. Chuah, H.-J.E. Chun, R.J.N. Coope, N. Dhalla, R. Guin, C. Hirst, M. Hirst, R.A. Holt, D. Lee, H.I. Li, M. Mayo, R.A. Moore, A.J. Mungall, E. Pleasance, A.G. Robertson, J.E. Schein, A. Shafiei, P. Sipahimalani, J.R. Slobodan, D. Stoll, A. Tam, N. Thiessen, R.J. Varhol, N. Wye, T. Zeng, Y. Zhao, I. Birol, S.J.M. Jones, M.A. Marra, A.D. Cherniack, G. Saksena, R.C. Onofrio, N.H. Pho, S.L. Carter, S.E. Schumacher, B. Tabak, B. Hernandez, J. Gentry, H. Nguyen, A. Crenshaw, K. Ardlie, R. Beroukhim, W. Winckler, G. Getz, S.B. Gabriel, M. Meyerson, L. Chin, P.J. Park, R. Kucherlapati, K.A. Hoadley, J.T. Auman, C. Fan, Y.J. Turman, Y. Shi, L. Li, M.D. Topal, X. He, H.-H. Chao, A. Prat, G.O. Silva, M.D. Iglesia, W. Zhao, J. Usary, J.S. Berg, M. Adams, J. Booker, J. Wu, A. Gulabani, T. Bodenheimer, A.P. Hoyle, J.V. Simons, M.G. Soloway, L.E. Mose, S.R. Jefferys, S. Balu, J.S. Parker, D.N. Hayes, C.M. Perou, S. Malik, S. Mahurkar, H. Shen, D.J. Weisenberger, T. Triche Jr., P.H. Lai, M.S. Bootwalla, D.T. Maglinte, B.P. Berman, D.J. Van Den Berg, S.B. Baylin, P.W. Laird, C.J. Creighton, L.A. Donehower, G. Getz, M. Noble, D. Voet, G. Saksena, N. Gehlenborg, D. DiCara, J. Zhang, H. Zhang, C.-J. Wu, S.Y. Liu, M.S. Lawrence, L. Zou, A. Sivachenko, P. Lin, P. Stojanov, R. Jing, J. Cho, R. Sinha, R.W. Park, M.-D. Nazaire, J. Robinson, H. Thorvaldsdottir, J. Mesirov, P.J. Park, L. Chin, S. Reynolds, R.B. Kreisberg, B. Bernard, R. Bressler, T. Erkkila, J. Lin, V. Thorsson, W. Zhang, I. Shmulevich, G. Ciriello, N. Weinhold, N. Schultz, J. Gao, E. Cerami, B. Gross, A. Jacobsen, R. Sinha, B.A. Aksoy, Y. Antipin, B. Reva, R. Shen, B.S. Taylor, M. Ladanyi, C. Sander, P. Anur, P.T. Spellman, Y. Lu, W. Liu, R.R.G. Verhaak, G.B. Mills, R. Akbani, N. Zhang, B.M. Broom, T.D. Casasent, C. Wakefield, A.K. Unruh, K. Baggerly, K. Coombes, J.N. Weinstein, D. Haussler, C.C. Benz, J.M. Stuart, S.C. Benz, J. Zhu, C.C. Szeto, G.K. Scott, C. Yau, E.O. Paull, D. Carlin, C. Wong, A. Sokolov, J. Thusberg, S. Mooney, S. Ng, T.C. Goldstein, K. Ellrott, M. Grifford, C. Wilks, S. Ma, B. Craft, C. Yan, Y. Hu, D. Meerzaman, J.M. Gastier-Foster, J. Bowen, N.C. Ramirez, A.D. Black, R.E. Pyatt, P. White, E.J. Zmuda, J. Frick, T.M. Lichtenberg, R. Brookens, M.M. George, M.A. Gerken, H.A. Harper, K.M. Leraas, L.J. Wise, T.R. Tabler, C. McAllister, T. Barr, M. Hart-Kothari, K. Tarvin, C. Saller, G. Sandusky, C. Mitchell, M.V. Iacocca, J. Brown, B. Rabeno, C. Czerwinski, N. Petrelli, O. Dolzhansky, M. Abramov, O. Voronina, O. Potapova, J.R. Marks, W.M. Suchorska, D. Murawa, W. Kycler, M. Ibbs, K. Korski, A. Spychała, P. Murawa, J.J. Brzeziński, H. Perz, R. Łaźniak, M. Teresiak, H. Tatka, E. Leporowska, M. Bogusz-Czerniewicz, J. Malicki, A. Mackiewicz, M. Wiznerowicz, X. Van Le, B. Kohl, N.V. Tien, R. Thorp, N. Van Bang, H. Sussman, B.D. Phu, R. Hajek, N.P. Hung, T.V.T. Phuong, H.Q. Thang, K.Z. Khan, R. Penny, D. Mallery, E. Curley, C. Shelton, P. Yena, J.N. Ingle, F.J. Couch, W.L. Lingle, T.A. King, A.M. Gonzalez-Angulo, G.B. Mills, M.D. Dyer, S. Liu, X. Meng, M. Patangan, N. The Cancer Genome Atlas, L. Genome sequencing centres: Washington University in St, B.C.C.A. Genome characterization centres, I. Broad, Brigham, H. Women's, S. Harvard Medical, C.H. University of North Carolina, H. University of Southern California/Johns, M. Genome data analysis: Baylor College of, B. Institute for Systems, C. Memorial Sloan-Kettering Cancer, H. Oregon, U. Science, M.D.A.C.C. The University of Texas, S.C.B.I. University of California, Nci, R. Biospecimen core resource: Nationwide Children's Hospital Biospecimen Core, A.-I. Tissue source sites, Christiana, Cureline, C. Duke University
Medical, C. The Greater Poland Cancer, Ilsbio, C. International Genomics, C. Mayo, Mskcc and M.D.A.C. Center, Comprehensive molecular portraits of human breast tumours. Nature 490, 61-70 (2012). https://doi.org/10.1038/nature11412

47. T.J. Robinson, J.C. Liu, F. Vizeacoumar, T. Sun, N. Maclean, S.E. Egan, A.D. Schimmer, A. Datti, E. Zacksenhaus, RB1 status in triple negative breast cancer cells dictates response to radiation treatment and selective therapeutic drugs. PLoS One 8, e78641 (2013). https://doi.org/10.1371/journal.pone.0078641

48. P. Russo, A. Del Bufalo, M. Milic, G. Salinaro, M. Fini, A. Cesario, Cholinergic receptors as target for cancer therapy in a systems medicine perspective. Curr Mol Med 14, 1126-1138 (2014)

49. J.J. Pink, V.C. Jordan, Models of estrogen receptor regulation by estrogens and antiestrogens in breast cancer cell lines. Cancer Res 56, 2321-2330 (1996)

50. M.C. Alles, M. Gardiner-Garden, D.J. Nott, Y. Wang, J.A. Foekens, R.L. Sutherland, E.A. Musgrove, C.J. Ormandy, Metaanalysis and gene set enrichment relative to er status reveal elevated activity of MYC and E2F in the "basal" breast cancer subgroup. PLoS One 4, e4710 (2009). https://doi.org/10.1371/journal.pone. 0004710

51. L. Verlinden, I.V. Bempt, G. Eelen, M. Drijkoningen, I. Verlinden, K. Marchal, C. De Wolf-Peeters, M.R. Christiaens, L. Michiels, R. Bouillon, A. Verstuyf, The E2F-regulated gene Chk1 is highly expressed in triple-negative estrogen receptor-/progesterone receptor-/HER-2- breast carcinomas. Cancer Res 67, 6574-6581 (2007). https://doi.org/10.1158/0008-5472.CAN-06-3545

52. C.-H. Lin, H.-H. Lee, C.-H. Kuei, H.-Y. Lin, L.-S. Lu, F.-P. Lee, J. Chang, J.-Y. Wang, K.-C. Hsu, Y.-F. Lin, Nicotinic acetylcholine receptor subunit Alpha-5 promotes radioresistance via recruiting E2F activity in oral squamous cell carcinoma. J Clin Med 8, 1454 (2019)

53. W. Wang, L. Dong, B. Saville, S. Safe, Transcriptional activation of E2F1 gene expression by 17beta-estradiol in MCF-7 cells is regulated by NF-Y-Sp1/estrogen receptor interactions. Mol Endocrinol 13, 1373-1387 (1999). https://doi.org/10.1210/mend.13.8.0323

54. K. Dahlman-Wright, Y. Qiao, P. Jonsson, J. Gustafsson, C. Williams, C. Zhao, Interplay between AP-1 and estrogen receptor $\alpha$ in regulating gene expression and proliferation networks in breast cancer cells. Carcinogenesis 33, 1684-1691 (2012). https://doi.org/ 10.1093/carcin/bgs223

55. J. Lukas, B.O. Petersen, K. Holm, J. Bartek, K. Helin, Deregulated expression of E2F family members induces S-phase entry and overcomes p16INK4A-mediated growth suppression. Mol Cell Biol 16, 1047-1057 (1996). https://doi.org/10.1128/mcb.16.3.1047

56. H. Singhal, M.E. Greene, A.L. Zarnke, M. Laine, R. Al Abosy, Y.F. Chang, A.G. Dembo, K. Schoenfelt, R. Vadhi, X. Qiu, P. Rao, B. Santhamma, H.B. Nair, K.J. Nickisch, H.W. Long, L. Becker, M. Brown, G.L. Greene, Progesterone receptor isoforms, agonists and antagonists differentially reprogram estrogen signaling. Oncotarget 9, 4282-4300 (2018). https://doi.org/10.18632/oncotarget.21378

57. R. Mahadevappa, H. Neves, S.M. Yuen, Y. Bai, C.M. McCrudden, H.F. Yuen, Q. Wen, S.D. Zhang, H.F. Kwok, The prognostic significance of Cdc6 and Cdt1 in breast cancer. Sci Rep 7, 985 (2017). https://doi.org/10.1038/s41598-017-00998-9

58. G. Nassa, R. Tarallo, G. Giurato, M.R. De Filippo, M. Ravo, F. Rizzo, C. Stellato, C. Ambrosino, M. Baumann, N. Lietzèn, T.A. Nyman, A. Weisz, Post-transcriptional regulation of human breast cancer cell proteome by unliganded estrogen receptor $\beta$ via microRNAs. Mol Cell Proteomics 13, 1076-1090 (2014). https:// doi.org/10.1074/mcp.M113.030403

59. E.V. Jensen, G. Cheng, C. Palmieri, S. Saji, S. Mäkelä, S. Van Noorden, T. Wahlström, M. Warner, R.C. Coombes, J.A. Gustafsson, Estrogen receptors and proliferation markers in primary and recurrent breast cancer. Proc Natl Acad Sci U S A 98, 15197-15202 (2001). https://doi.org/10.1073/pnas.211556298 
60. U.K. Mukhopadhyay, C.C. Oturkar, C. Adams, N. Wickramasekera, S. Bansal, R. Medisetty, A. Miller, W.M. Swetzig, L. Silwal-Pandit, A.-L. Børresen-Dale, C.J. Creighton, J.H. Park, S.D. Konduri, A. Mukhopadhyay, A. Caradori, A. Omilian, W. Bshara, B.A. Kaipparettu, G.M. Das, TP53 status as a determinant of pro- vs anti-tumorigenic effects of estrogen receptor-beta in breast cancer. J Natl Cancer Inst 111, 1202-1215 (2019). https://doi.org/10.1093/jnci/djz051

61. S.K. Gruvberger-Saal, P.-O. Bendahl, L.H. Saal, M. Laakso, C. Hegardt, P. Edén, C. Peterson, P. Malmström, J. Isola, Å. Borg, Estrogen receptor $\beta$ expression is associated with tamoxifen response in $E R \alpha$-negative breast carcinoma. Clin Cancer Res 13, 1987-1994 (2007)

62. P. O'neill, M. Davies, A. Shaaban, H. Innes, A. Torevell, D. Sibson, C. Foster, Wild-type oestrogen receptor beta (ER $\beta 1)$ mRNA and protein expression in Tamoxifen-treated post-menopausal breast cancers. Br J Cancer 91, 1694-1702 (2004)

63. R. Girgert, G. Emons, C. Gründker, Estrogen signaling in ER $\alpha-$ negative breast cancer: ER $\beta$ and GPER. Front Endocrinol 9, 781 (2018)

64. L.-H. Hsu, N.-M. Chu, Y.-F. Lin, S.-H. Kao, G-protein coupled estrogen receptor in breast cancer. Int J Mol Sci 20, 306 (2019)

65. L. Salvatori, L. Ravenna, F. Caporuscio, L. Principessa, G. Coroniti, L. Frati, M.A. Russo, E. Petrangeli, Action of retinoic acid receptor on EGFR gene transactivation and breast cancer cell proliferation: Interplay with the estrogen receptor. Biomed Pharmacother 65, 307-312 (2011)

66. V.C. Jordan, R. Curpan, P.Y. Maximov, Estrogen receptor mutations found in breast cancer metastases integrated with the molecular pharmacology of selective ER modulators. J Natl Cancer Inst 107, djv075 (2015)

67. F.J. Fleming, A.D. Hill, E.W. McDermott, N.J. O'Higgins, L.S. Young, Differential recruitment of coregulator proteins steroid receptor coactivator- 1 and silencing mediator for retinoid and thyroid receptors to the estrogen receptor-estrogen response element by $\beta$ estradiol and 4-hydroxytamoxifen in human breast cancer. J Clin Endocrinol Metabol 89, 375-383 (2004)

68. E.N. Lyukmanova, M.L. Bychkov, G.V. Sharonov, A.V. Efremenko, M.A. Shulepko, D.S. Kulbatskii, Z.O. Shenkarev, A.V. Feofanov, D.A. Dolgikh, M.P. Kirpichnikov, Human secreted proteins SLURP-1 and SLURP-2 control the growth of epithelial cancer cells via interactions with nicotinic acetylcholine receptors. Br J Pharmacol 175, 1973-1986 (2018). https://doi.org/ 10.1111/bph.14194

69. A.R. Salem, P. Martínez Pulido, F. Sanchez, Y. Sanchez, A.J. Español, M.E. Sales, Effect of low dose metronomic therapy on MCF-7 tumor cells growth and angiogenesis. Role of muscarinic acetylcholine receptors Int Immunopharmacol 84, 106514 (2020). https://doi.org/10.1016/j.intimp.2020.106514

70. T.I. Terpinskaya, A.V. Osipov, T.V. Balashevich, T.L. Yanchanka, E.A. Tamashionik, V.I. Tsetlin, Y.N. Utkin, Blockers of nicotinic acetylcholine receptors delay tumor growth and increase antitumor activity of mouse splenocytes. Dokl Biochem Biophys 491, 89-92 (2020). https://doi.org/10.1134/S1607672920020143

71. Z. Sun, J. Bao, M. Zhangsun, S. Dong, D. Zhangsun, S. Luo, $\alpha \mathrm{O}-$ Conotoxin GeXIVA inhibits the growth of breast cancer cells via interaction with $\alpha 9$ nicotine acetylcholine receptors. Marine drugs 18, 195 (2020). https://doi.org/10.3390/md18040195

72. S.A. Ochsner, D.L. Steffen, S.G. Hilsenbeck, E.S. Chen, C. Watkins, N.J. McKenna, GEMS (gene expression MetaSignatures), a web resource for querying meta-analysis of expression microarray datasets: 17beta-estradiol in MCF-7 cells. Cancer Res 69, 23-26 (2009). https://doi.org/10.1158/0008-5472. CAN-08-3492

73. D.R. Rhodes, J. Yu, K. Shanker, N. Deshpande, R. Varambally, D. Ghosh, T. Barrette, A. Pandey, A.M. Chinnaiyan, Large-scale meta-analysis of cancer microarray data identifies common transcriptional profiles of neoplastic transformation and progression. Proc Natl Acad Sci U S A 101, 9309-9314 (2004). https://doi.org/10. 1073/pnas.0401994101

74. B.J. Wilson, V. Giguere, Meta-analysis of human cancer microarrays reveals GATA3 is integral to the estrogen receptor alpha pathway. Mol Cancer 7, 49 (2008). 10.1186/1476-4598-7-49

75. D.D. Smith, P. Saetrom, O. Snove Jr., C. Lundberg, G.E. Rivas, C. Glackin, G.P. Larson, Meta-analysis of breast cancer microarray studies in conjunction with conserved cis-elements suggest patterns for coordinate regulation. BMC Bioinformatics 9, 63 (2008). https://doi.org/10.1186/1471-2105-9-63

Publisher's note Springer Nature remains neutral with regard to jurisdictional claims in published maps and institutional affiliations. 